\title{
Disorder of Coagulation-Fibrinolysis System: An Emerging Toxicity of Anti-PD-1/PD-L1 Monoclonal Antibodies
}

\author{
Ryo Sato ${ }^{1,+}$, Kosuke Imamura $^{1,+}{ }^{+}$, Shinya Sakata ${ }^{1}$, Tokunori Ikeda ${ }^{2}$, Yuko Horio ${ }^{1}$, Shinji Iyama ${ }^{1}$, \\ Kimitaka Akaike ${ }^{1}$, Shohei Hamada ${ }^{1}$, Takayuki Jodai ${ }^{1}$, Kei Nakashima ${ }^{1}$, Shiho Ishizuka ${ }^{1}$, \\ Nahoko Sato ${ }^{1}$, Koichi Saruwatari ${ }^{1}$, Sho Saeki ${ }^{1}$, Yusuke Tomita ${ }^{1, *}$ ) and Takuro Sakagami ${ }^{1}$ \\ 1 Department of Respiratory Medicine, Graduate School of Medical Sciences, Kumamoto University, \\ Honjo 1-1-1, Chuo-ku, Kumamoto-shi, Kumamoto 860-8556, Japan; ryosato.1981@gmail.com (R.S.); \\ imakou1013@gmail.com (K.I.); sakata-1027@hotmail.co.jp (S.S.); yu1980327@gmail.com (Y.H.); \\ iyama.shinji@kuh.kumamoto-u.ac.jp (S.I.); demio0601@gmail.com (K.A.); unagicurry@yahoo.co.jp (S.H.); \\ jojojojojody@gmail.com (T.J.); keinakasima056@gmail.com (K.N.); zhi4_sui4@yahoo.co.jp (S.I.); \\ nahoko.t.k.d@gmail.com (N.S.); ksaruwat@kuh.kumamoto-u.ac.jp (K.S.); \\ saeshow@kuh.kumamoto-u.ac.jp (S.S.); stakuro@kumamoto-u.ac.jp (T.S.) \\ 2 Department of Clinical Investigation, Kumamoto University Hospital, Honjo 1-1-1, Chuo-ku, Kumamoto-shi, \\ Kumamoto 860-8556, Japan; ryousei@kumamoto-u.ac.jp \\ * Correspondence: y-tomita@kumadai.jp; Tel.: +81-96-373-5012; Fax: +81-96-373-5328 \\ + Theses authors contributed equally to this work.
}

Received: 3 May 2019; Accepted: 27 May 2019; Published: 29 May 2019

\begin{abstract}
A disruption of immune checkpoints leads to imbalances in immune homeostasis, resulting in immune-related adverse events. Recent case studies have suggested the association between immune checkpoint inhibitors (ICIs) and the disorders of the coagulation-fibrinolysis system, implying that systemic immune activation may impact a balance between clotting and bleeding. However, little is known about the association of coagulation-fibrinolysis system disorder with the efficacy of ICIs. We retrospectively evaluated 83 lung cancer patients who received ICI at Kumamoto University Hospital. The association between clinical outcome and diseases associated with disorders of the coagulation-fibrinolysis system was assessed along with tumor PD-L1 expression. Among 83 NSCLC patients, total 10 patients (12\%) developed diseases associated with the disorder of coagulation-fibrinolysis system. We found that disorders of the coagulation-fibrinolysis system occurred in patients with high PD-L1 expression and in the early period of ICI initiation. In addition, high tumor responses (72\%) were observed, including two complete responses among these patients. Furthermore, we demonstrate T-cell activation strongly induces production of a primary initiator of coagulation, tissue factor in peripheral PD-L1 ${ }^{\text {high }}$ monocytes, in vitro. This study suggests a previously unrecognized pivotal role for immune activation in triggering disorders of the coagulation-fibrinolysis system in cancer patients during treatment with ICI.
\end{abstract}

Keywords: immune-related adverse events (irAEs); immune checkpoint inhibitor (ICI); non-small-cell lung cancer (NSCLC); programmed cell death 1 (PD-1); programmed cell death ligand 1 (PD-L1); $\mathrm{T}$ cell; tissue factor (TF); Trousseau's syndrome; monocyte; macrophage

\section{Introduction}

$\mathrm{T}$ cell activation and proliferation are initiated through antigen recognition by the $\mathrm{T}$ cell receptor (TCR). The T cell response is regulated by a balance between co-stimulatory and inhibitory signals called immune checkpoints [1]. Under normal physiological conditions, immune checkpoints play 
a crucial role in maintaining immune homeostasis and preventing autoimmunity [1]. In cancer, immune checkpoint pathways delivering inhibitory signals are often activated to suppress anti-tumor immune response in tumor immune microenvironments as one of the mechanisms of tumor immune escape [2-5].

The first generation of antibody-based immunotherapy, called immune checkpoint inhibitors (ICIs), blocks the receptor and/or ligand interactions of molecules, such as cytotoxic T-lymphocyte antigen 4 (CTLA-4), programmed cell death 1 (PD-1), and programmed cell death ligand 1 (PD-L1) [1,5]. Anti-PD-1/PD-L1 antibodies inhibit the interaction between PD-1 and PD-L1 and unleash immune responses against tumors: activating or boosting the activation of the immune system to attack cancer cells [6]. The immunotherapy targeting the PD-1/PD-L1 pathway has shown significant and durable clinical responses for non-small-cell lung cancer (NSCLC) patients in addition to a more favorable toxicity profile and improved tolerability than chemotherapy [7]. Anti-PD-1/PD-L1 antibody therapy has changed the treatment landscape and led to a paradigm shift in treatment strategies in NSCLC, and is now a standard-of-care for NSCLC [6-8]. ICI are recognized as a promising strategy to treat various types of cancer and the indications for the use of ICIs continue to expand with unprecedented speed [5-8].

A disruption of inhibitory immune checkpoint leads to imbalances in immune homeostasis, resulting in adverse effects which are termed immune-related adverse events (irAEs) that share clinical features with autoimmune diseases or inflammatory diseases [9]. The irAEs can affect multiple organs of the body and are commonly seen in the skin, lungs, thyroid, endocrine, adrenal, pituitary, gastrointestinal tract, musculoskeletal, renal, and nervous system $[9,10]$. Most of the irAEs are usually reversible, but in rare cases, they can be severe and life-threatening. In addition, unexpected severe irAEs have emerged in real-world clinical practice [11-15]. Thus, elucidating mechanisms of irAEs is urgently needed to improve their early diagnosis and develop more precise treatments for irAEs $[9,10]$.

A balance between clotting and bleeding is maintained in normal physiology, but can be altered under the presence of malignancies [16-18]. It has been known that a coagulation homeostasis could be further impaired after nonsurgical cancer therapy including radiation therapy, standard chemotherapy, and targeted therapy, which could trigger both bleeding and thrombosis; however, the underlying mechanisms remain unclear [18-20]. Recently, several case studies have suggested that anti-PD-1/PD-L1 monoclonal antibodies might trigger disorders of the coagulation-fibrinolysis system in advanced cancer patients, which implies that the systemic immune activation may impact a balance between clotting and bleeding $[13,14,21-23]$. However, the association of coagulation-fibrinolysis system disorder with the efficacy of anti-PD-1/PD-L1 monoclonal antibody therapies and clinical characteristics of the patients who develop diseases associated with disorders of the coagulation-fibrinolysis system under treatment with ICIs have not been studied yet.

Tissue factor (TF) is a transmembrane cell surface glycoprotein that triggers the extrinsic coagulation cascade and is essential for hemostasis. TF binds the coagulation serine protease factor VII/VIIa (FVII/VIIa) to form a bimolecular complex that functions as the primary initiator of coagulation in vivo $[24,25]$. Studies have shown that levels of circulating TF in the form of microparticles are increased in various diseases, including cardiovascular disease, sepsis, and cancer [16,26]. In addition, circulating TF in blood has been suggested to be a cause of distant thromboses and contributes to the increased incidence of thrombosis observed in these diseases. Importantly, monocytes have been shown to be the major source of intravascular TF in many diseases $[16,25,27]$. Therefore, we focused on the relationship between $\mathrm{T}$ cell activation and induction of TF expression on monocytes in peripheral blood mononuclear cells (PBMCs) in this study.

Here, we report the clinical features of NSCLC patients who developed diseases associated with disorders of the coagulation-fibrinolysis system during treatment with ICI. We demonstrate that $\mathrm{T}$ cell activation leads to promoting production of a primary initiator of coagulation, TF, in PD-L1 high human peripheral $\mathrm{CD} 14^{+}$monocytes. We also discuss the underlying mechanisms of the onset of disorders of coagulation-fibrinolysis system as an irAE of anti-PD-1/PD-L1 antibody therapy. This 
study suggests a previously unrecognized pivotal role for immune activation in triggering disorders of coagulation-fibrinolysis system in advanced cancer patients during treatment with ICI monotherapy.

\section{Materials and Methods}

\subsection{Patients}

The medical records of patients with advanced NSCLC who had received nivolumab $(3 \mathrm{mg} / \mathrm{kg}$ every 2 weeks), pembrolizumab (200 mg every 3 weeks), or atezolizumab (1200 mg every 3 weeks) monotherapy at Kumamoto University Hospital between January 2016 and October 2018 were retrospectively reviewed. Treatments were provided until disease progression, unacceptable toxicity, or consent withdrawal. The present study was approved by the Kumamoto University Institutional Review Board (IRB number, 1685, Approval Date, 27 March 2018.)

To maximally characterize the clinical features of NSCLC patients who developed diseases associated with disorders of the coagulation-fibrinolysis system during immune checkpoint blockade therapy, we searched the PubMed database. We did not limit search dates and we looked for articles published in English.

\subsection{Assessments}

Only adverse events associated with disorders of the coagulation-fibrinolysis system (thromboembolic and bleeding complications), which were not detected before treatment with ICI and newly developed during treatments with ICI (within 30 days of the last administration of ICI), were considered as disorders of the coagulation-fibrinolysis system possibly triggered by immune checkpoint blockade. The clinical severity of coagulation-fibrinolysis system disorders was graded according to the Common Terminology Criteria for Adverse Events, version 5.0. A newly developed purpura involving more than $10 \%$ of the body surface area (grade $\geq 2$ ) was assessed as one of the bleeding complications. Disorders of the coagulation-fibrinolysis system accompanied with the abnormal decrease in platelet count less than $100 \times 10^{9} / \mathrm{L}$ were not considered as coagulation-fibrinolysis system disorders triggered by ICI to exclude immune thrombocytopenia which previously reported as a rare irAE $[17,28]$. Tumor response to nivolumab, pembrolizumab, or atezolizumab monotherapy was objectively assessed by pulmonary physicians according to Response Evaluation Criteria in Solid Tumors, version 1.1. The Kaplan-Meier method was used to obtain estimates of progression-free survival (PFS) and overall survival (OS). PFS was measured from the date ICIs started to the date of documented progression or death. Patients who were alive and not known to have progressed were censored. OS was measured from the date ICI started to the date of death or last follow-up. The data cutoff date was 15 March 2019. $95 \%$ confidence intervals of survival were calculated by the log-log transformation of survival. The analysis was performed using GraphPad Prism 7.0c software (GraphPad Software, San Diego, CA, USA).

\subsection{PD-L1 Staining}

PD-L1 expression in the lung cancer specimen was analyzed by immunohistochemical staining using the PD-L1 IHC 22C3 pharmDx antibody (clone 22C3, Dako North America, Inc., Carpinteria, CA, USA). The antibody was applied according to DAKO-recommended detection methods. PD-L1 expression in tumor cells was scored as the percentage of stained cells.

\subsection{Isolation of PBMCs}

Blood samples of healthy donors were collected in cell preparation tubes with sodium citrate (BD Vacutainer CPT Tubes, BD Biosciences, Franklin Lakes, NJ, USA). PBMCs were obtained by centrifugation following the manufacturer's protocol. 


\subsection{In Vitro Assay}

Isolated PBMCs of healthy donors $\left(2 \times 10^{6} /\right.$ well $)$ were activated with lipopolysaccharide (LPS) (100 ng/mL; Escherichia coli 0111:B4, Sigma-Aldrich, St. Louis, MO, USA) or CD3/CD28/CD2 beads (T-cell Activation/Expansion Kit, Miltenyi Biotec, Bergisch Gladbach, Germany) for $18 \mathrm{~h}$ in 24-well flat bottom plates with 2 mL RPMI 1640 medium (FUJIFILM Wako Pure Chemical Corporation, Osaka, Japan) supplemented with 10\% fetal bovine serum (Biological Industries, Kibbutz Beit Haemek, Israel) at $37^{\circ} \mathrm{C}$ and $5 \% \mathrm{CO} 2$. After $18 \mathrm{~h}$, flow cytometric analysis and immunofluorescence staining were performed.

\subsection{Flow Cytometric Analyses}

Multiparameter flow cytometric analysis was performed on PBMCs. Briefly, cells were incubated with Fc receptor blocking agent (Miltenyi Biotec, Bergisch Gladbach, Germany) and stained with monoclonal antibodies for $20 \mathrm{~min}$ at $4{ }^{\circ} \mathrm{C}$ in a darkened room. CD3 and CD14 immunophenotypic markers were used to define $\mathrm{T}$ lymphocytes and monocytes. Each population was also evaluated for CD142 (tissue factor; TF), and PD-L1 expression. The following monoclonal antibodies were used (all from BioLegend, San Diego, CA, USA): FITC-CD3 clone OKT3, PerCP/Cy5.5-CD14 clone HCD14, APC-CD69 clone FN50, PE-CD142 clone NY2, PE/Cy7-HLA-DR clone L243, Brilliant Violet 421-PD-L1 clone 29E.2A3 were used. Matched isotype controls were used for each antibody to establish the gates. Live cells were discriminated by means of LIVE/DEAD Fixable Aqua Dead Cell Stain (Thermo Fisher Scientific, Waltham, MA, USA) and dead cells were excluded from all analyses. All flow cytometric analyses were performed using a BD FACSVerse ${ }^{\mathrm{TM}}$ (BD, Franklin Lakes, NJ, USA). Data were analyzed using FlowJo software (FlowJo LLC, Ashland, OR, USA).

\subsection{Immunofluorescence Staining}

Immunofluorescence staining was performed on PBMCs. Briefly, cells were incubated with Fc receptor blocking agent (Miltenyi Biotec, Bergisch Gladbach, Germany) and stained with monoclonal antibodies for $20 \mathrm{~min}$ at $4{ }^{\circ} \mathrm{C}$ in a darkened room. The following monoclonal antibodies were used (all from BioLegend, San Diego, CA, USA): FITC-CD3 clone OKT3, PerCP/Cy5.5-CD14 clone HCD14, APC-CD69 clone FN50, PE-CD142 clone NY2. After fixation of stained cells using Fix/Perm buffer (Thermo Fisher Scientific, Waltham, MA, USA), the suspension of fixed cells was immobilized onto glass slides by cytospin. Nuclei were counter stained with 4',6-diamidino-2-phenylindole dihydrochloride (DAPI) (DOJINDO, Kumamoto, Japan) in water, and whole sections were mounted in ProLong Diamond (Thermo Fisher Scientific, Waltham, MA, USA). Slides were observed with a confocal fluorescence microscope (FV3000, Olympus, Tokyo, Japan).

\section{Results}

\subsection{Disorder of Coagulation-Fibrinolysis System Triggered by Immune Checkpoint Blockade in Advanced Lung Cancer}

Only diseases associated with disorders of coagulation-fibrinolysis system occurred during treatment with ICI were considered as the possible irAEs triggered by immune checkpoint blockade [13, $14,21,22,29$ ]. Disorders of the coagulation-fibrinolysis system accompanied with the abnormal decrease in platelet count were not considered as coagulation-fibrinolysis system disorders triggered by ICI to exclude immune thrombocytopenia which previously reported as a rare irAE [28]. Disseminated intravascular coagulation (DIC) caused by pneumonia and sepsis accompanied with elevations of procalcitonin in blood were seen in two patients during treatment with ICI. However, ICI-related DIC without infectious diseases was not observed in current study. Thus, the two patients who developed DIC were not considered as having coagulation-fibrinolysis system disorders triggered by ICI.

Among 83 advanced NSCLC patients receiving nivolumab, pembrolizumab, or atezolizumab monotherapy at Kumamoto University Hospital between January 2016 and October 2018, a total of 
10 patients (12\%) developed diseases associated with the disorder of coagulation-fibrinolysis system (thromboembolic and bleeding complications) during treatment with ICI, of which 2 patients were cases recently reported from our group [13,14]. To maximally characterize the clinical features of NSCLC patients who developed diseases associated with disorders of the coagulation-fibrinolysis system during immune checkpoint blockade therapy, we added two NSCLC cases identified by the PubMed database search to this study [22,29]. Ferreira et al. have shown a case of NSCLC patient who had an acute coronary syndrome (ACS) during the second administration of nivolumab (Tables 1 and 2) [22]. Kunimasa et al. have reported a case of deep vein thrombosis (DVT) and pulmonary thromboembolism (PTE) associated with pembrolizumab in NSCLC patient (Tables 1 and 2) [29]. The characteristics of a total 12 patients who developed diseases associated with disorder of the coagulation-fibrinolysis system are summarized in Tables 1 and 2.

The median age was 70.5 (range, 48-81) years. Of 12 patients, four (33\%) were diagnosed as having squamous cell carcinoma and eight (67\%) were diagnosed as having nonsquamous NSCLC. Mutation (L858R) in epidermal growth factor receptor (EGFR) was present in one patient (8\%). Six patients $(50 \%)$ had undergone no prior chemotherapy regimen, whereas 6 of 12 patients $(50 \%)$ had received one or more previous chemotherapies. The median treatment line was 1.5 (range, 1-4).

A broad spectrum of diseases associated with disorders of coagulation-fibrinolysis system including ACS $(n=2)$, cerebral infarcts $(\mathrm{CI} ; n=5$; Figure 1 , case 4$)$, DVT $(n=3$; Figure 1, case 9), PTE $(n=1)$, intra brain tumor hemorrhage $(n=1)$, gastrointestinal bleeding $(n=2)$, purpura involving more than $10 \%$ of the body surface area $(n=2)$, and bronchial hemorrhage $(n=2)$ associated with the administrations of ICIs was observed (Table 1). Of the 12 patients, 11 were treated with anti-PD-1 monoclonal antibodies (nivolumab or pembrolizmab), while 1 patient received an anti-PD-L1 monoclonal antibody (atezolizumab). The severe grade ( $\geq$ Grade 3 ) of diseases associated with disorders of coagulation-fibrinolysis system were seen in 4 out of 12 patients (33\%). One death related to intra brain-tumor hemorrhage was observed. The first onset of diseases associated with disorder of coagulation-fibrinolysis system developed within 2 cycles of anti-PD-1/PD-L1 monoclonal antibody therapies for 8 patients (67\%), with a median onset of 1 cycle (range 1-16 cycles) (Table 1 ). Among 12 patients, 4 patients had past medical history of diseases associated with disorders of coagulation-fibrinolysis system. Three of the 4 patients had been taking antiplatelet agents (Table 2). Antiangiogenic agents including bevacizumab have not been used prior to ICI in these 12 patients. 
Table 1. Clinical features of NSCLC patients who developed diseases associated with disorders of coagulation-fibrinolysis system during immune checkpoint blockade therapy.

\begin{tabular}{|c|c|c|c|c|c|c|c|c|c|c|}
\hline Patient & Age/Gender & $\begin{array}{c}\text { Coagulation- fibrinolysis } \\
\text { System AE }\end{array}$ & $\begin{array}{l}\text { Hemorrhagic } \\
\text { Complication }\end{array}$ & $\begin{array}{l}\text { CTCAE } \\
\text { Grade }\end{array}$ & $\begin{array}{l}\text { Therapeutic } \\
\text { Antibody/ } \\
\text { Treatment Line }\end{array}$ & $\begin{array}{l}\text { Onset } \\
\text { (Cycle) }\end{array}$ & $\begin{array}{l}\text { Histopathology/ } \\
\text { Clinical Stage }\end{array}$ & $\begin{array}{l}\text { PD-L1 } \\
\text { Expression }\end{array}$ & $\begin{array}{c}\text { Tumor } \\
\text { Response }\end{array}$ & Reference \\
\hline 1 & $60 / F$ & ACS & & 3 & Nivolumab/2 & 2 & Adeno/IVB & NE & PR & Ferreira et al. [22] \\
\hline 2 & $61 / \mathrm{M}$ & $\begin{array}{c}\text { ACS, } \\
\text { Cerebral lacunar infarction }\end{array}$ & & 3,1 & Nivolumab/3 & 11 & Adeno/IVB & $\geq 75 \%$ & $\mathrm{CR}$ & Tomita et al. [14] \\
\hline 3 & $63 / \mathrm{M}$ & $\begin{array}{l}\text { Multiple cerebral infarcts, } \\
\text { Intracranial hemorrhage }\end{array}$ & + & 3,5 & Pembrolizumab/1 & 1 & Adeno/IVB & $\geq 75 \%$ & SD & Horio et al., [13] \\
\hline 4 & $72 / \mathrm{M}$ & Multiple cerebral infarcts & & 1 & Atezolizumab/3 & 1 & $\begin{array}{l}\mathrm{Sq} / \mathrm{IIIA} \\
\text { recurrence }\end{array}$ & $\geq 50 \%$ & $\mathrm{NE}$ & \\
\hline 5 & $71 / \mathrm{M}$ & $\begin{array}{l}\text { Gastrointestinal bleeding, } \\
\text { Multiple cerebral infarcts }\end{array}$ & + & 2,1 & Pembrolizumab/1 & 1,6 & Adeno/IVB & $\geq 75 \%$ & $\mathrm{CR}$ & \\
\hline 6 & $67 / \mathrm{M}$ & $\begin{array}{l}\text { Cerebral microbleed and } \\
\text { lacunar infarction }\end{array}$ & + & 1 & Pembrolizumab/1 & 12 & $\mathrm{Sq} / \mathrm{IVB}$ & $80 \%$ & PR & \\
\hline 7 & $48 / \mathrm{F}$ & DVT, PTE & & 2,3 & Pembrolizumab/1 & 1 & Adeno/IVB & $\geq 90 \%$ & PR & Kunimasa et al. [29] \\
\hline 8 & $76 / \mathrm{M}$ & Purpura, DVT & + & 2,2 & Nivolumab/4 & 1,2 & $\begin{array}{c}\text { Adeno } \\
(\text { EGFRm)/IVB }\end{array}$ & $20-30 \%$ & PD & \\
\hline 9 & $68 / \mathrm{F}$ & $\begin{array}{c}\text { DVT, } \\
\text { Bronchial hemorrhage }\end{array}$ & + & 2,2 & Nivolumab/3 & 1,4 & Adeno/IVB & $1-24 \%$ & PR & \\
\hline 10 & $81 / \mathrm{M}$ & Bronchial hemorrhage & + & 2 & Nivolumab/3 & 16 & $\mathrm{Sq} / \mathrm{IVB}$ & $\geq 75 \%$ & PR & \\
\hline 11 & $74 / \mathrm{M}$ & Purpura & + & 2 & Pembrolizumab/1 & 4 & Adeno/IVB & $80 \%$ & PR & \\
\hline 12 & $79 / \mathrm{M}$ & Gastrointestinal bleeding & + & 2 & Pembrolizumab/1 & 1 & $\begin{array}{l}\mathrm{Sq} / \mathrm{IIIB} \\
\text { recurrence }\end{array}$ & $50-75 \%$ & SD & \\
\hline
\end{tabular}

Abbreviations: ACS, acute coronary syndrome; AE, adverse event; Adeno, adenocarcinoma; DVT, deep venous thrombosis; Sq, squamous cell carcinoma; SD, stable disease; PD, progression disease; PR, partial response; PTE, pulmonary thromboembolism; CR, complete response; $\mathrm{M}$, male; F, female; NE, not examend. A newly developed purpura involving more than $10 \%$ of the body surface area (grade $\geq 2$ ) was considered as disorders of coagulation-fibrinolysis system triggered by immune checkpoint blockade therapy in this study. 
Table 2. Past medical history of NSCLC patients who developed diseases associated with disorders of coagulation-fibrinolysis system during immune checkpoint blockade therapy.

\begin{tabular}{|c|c|c|c|c|c|c|}
\hline Patient & Age/Gender & $\begin{array}{c}\text { Coagulation-Fibrinolysis } \\
\text { System AE during ICI } \\
\text { Therapy }\end{array}$ & $\begin{array}{l}\text { Hemorrhagic } \\
\text { Complication }\end{array}$ & $\begin{array}{c}\text { Use of } \\
\text { Anticoagulants or } \\
\text { Antiplatelet Agents }\end{array}$ & $\begin{array}{l}\text { Past Medical History of Diseases } \\
\text { Associated with Disorders of } \\
\text { Coagulation-Fibrinolysis System }\end{array}$ & Reference \\
\hline 1 & $60 / \mathrm{F}$ & ACS & & none & none & Ferreira et al. [22] \\
\hline 2 & $61 / \mathrm{M}$ & $\begin{array}{c}\text { ACS, } \\
\text { Cerebral lacunar infarction }\end{array}$ & & none & none & Tomita et al. [14] \\
\hline 3 & $63 / \mathrm{M}$ & $\begin{array}{l}\text { Multiple cerebral infarcts, } \\
\text { Intracranial hemorrhage }\end{array}$ & + & none & none & Horio et al. [13] \\
\hline 4 & $72 / \mathrm{M}$ & Multiple cerebral infarcts & & none & none & \\
\hline 5 & $71 / \mathrm{M}$ & $\begin{array}{l}\text { Gastrointestinal bleeding, } \\
\text { Multiple cerebral infarcts }\end{array}$ & + & Aspirin, Clopidogrel & Coronary stenosis & \\
\hline 6 & $67 / \mathrm{M}$ & $\begin{array}{l}\text { Cerebral microbleed and } \\
\text { lacunar infarction }\end{array}$ & + & none & Cerebral bleed & \\
\hline 7 & $48 / \mathrm{F}$ & DVT, PTE & & none & none & $\begin{array}{c}\text { Kunimasa et al. } \\
\text { [29] }\end{array}$ \\
\hline 8 & $76 / \mathrm{M}$ & Purpura, DVT & + & none & none & \\
\hline 9 & $68 / \mathrm{F}$ & $\begin{array}{c}\text { DVT, } \\
\text { Bronchial hemorrhage }\end{array}$ & + & none & none & \\
\hline 10 & $81 / \mathrm{M}$ & Bronchial hemorrhage & + & $\begin{array}{c}\text { Aspirin, } \\
\text { Dipyridamole }\end{array}$ & Myocardial infarction & \\
\hline 11 & $74 / \mathrm{M}$ & Purpura & + & none & none & \\
\hline 12 & $79 / \mathrm{M}$ & Gastrointestinal bleeding & + & $\begin{array}{l}\text { Cilostazol, } \\
\text { Clopidogrel }\end{array}$ & Cerebral infarction & \\
\hline
\end{tabular}

Abbreviations: ACS, acute coronary syndrome; AE, adverse event; DVT, deep venous thrombosis; PTE, pulmonary thromboembolism. No patients have been taking anticoagulants. 


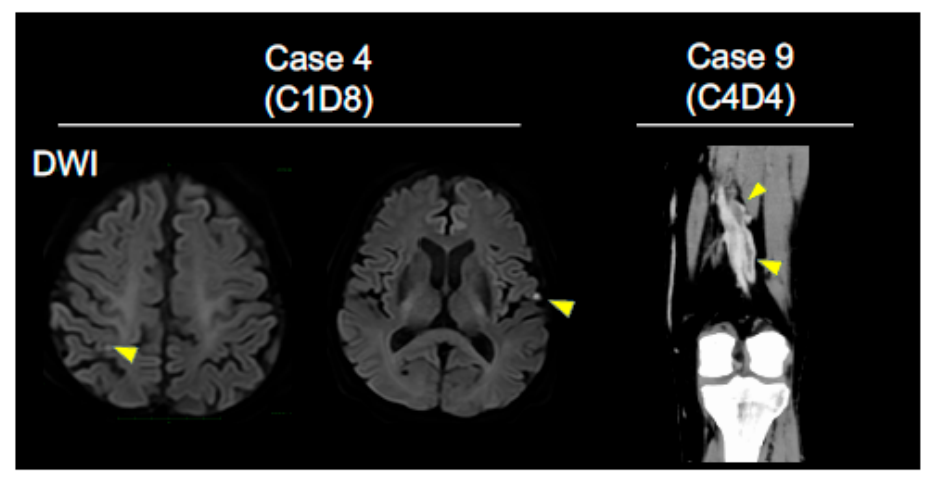

Figure 1. Key imaging in NSCLC patients who developed diseases associated with disorders of the coagulation-fibrinolysis. Brain MRI images (DWI) show multiple cerebral infarctions (arrowheads) (Case 4; cycle 1 day 8, C1D8, left panel). Contrast-enhanced CT image of leg vein shows deep vein thrombosis (arrowheads) (Case 9; C4D4, right panel).

3.2. Association of Coagulation-Fibrinolysis System Disorders with the Efficacy of Anti-PD-1/PD-L1 Monoclonal Antibody Therapies in NSCLC

The PD-L1 tumor proportion score (TPS) were evaluable in 11 of 12 patients who developed diseases associated with disorders of the coagulation-fibrinolysis system (Table 1). Interestingly, all 11 patients were positive for PD-L1. The expression of PD-L1 was abundant (TPS $\geq 50 \%$ ) in 9 of 11 patients (82\%) (Figure 2A) and at low levels $(1 \% \leq$ TPS $<50 \%)$ in 2 patients $(18 \%)$. The association between irAEs and the efficacy of anti-PD-1/PD-L1 monoclonal antibody therapies in NSCLC have been reported [5,30-33]. Of the 12 NSCLC patients, 11 were assessable for tumor response. One patient died 28 days after starting treatment due to pneumonia and was not assessable for response. Based on Response Evaluation Criteria in Solid Tumors, version 1.1, complete response (CR) was observed in two patients (17\%), partial response in six patients $(55 \%)$, stable disease in two patients $(18 \%)$, and progressive disease in one patient $(9 \%)$. The objective response rate (ORR) and the disease control rate (DCR) were $72 \%$ and $91 \%$, respectively in NSCLC patients evaluated for tumor response $(n=11)$ (Figure 2B). Of 12 NSCLC patients who developed diseases associated with disorders of the coagulation-fibrinolysis system, 10 were assessable for survival. The 10 patients analyzed for PFS and OS had received ICIs at Kumamoto University Hospital. The median PFS was 8.3 months (Figure 2C, left panel). The median OS was not reached (Figure 2C, right panel).

Chemotherapy and radiotherapy in patients with advanced cancer have been known to not only trigger coagulation disorders, but also enhance the risk of bleeding complications due to the local fibrinogen and platelet consumption and induction of endothelial injury [16-20,34]. In the current study, 7 out of 12 patients (58\%) had hemorrhagic complications after immune checkpoint blockade therapy (Table 1). Case 10, 11, and 12 showed only hemorrhagic complications (bronchial hemorrhage, gastrointestinal bleeding, and grade 2 purpura). Among hemorrhagic complications, hemorrhage from brain tumor (case 2, Table 1) was a grade 5 adverse event, suggesting clinicians should be aware of the risk of hemorrhagic complications during ICI therapy as a potential life-threatening irAE [13]. 
A

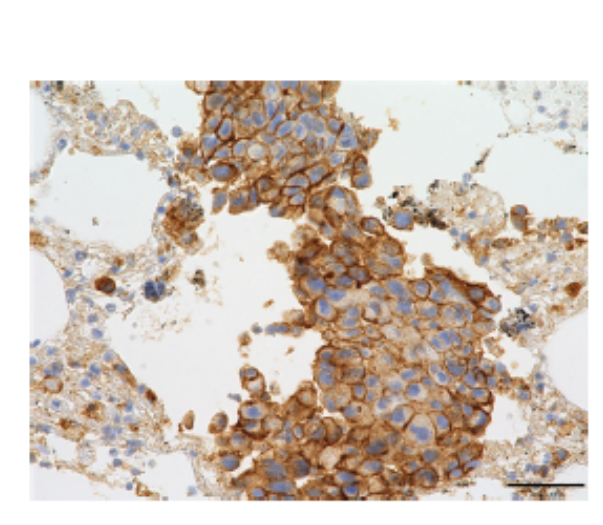

C

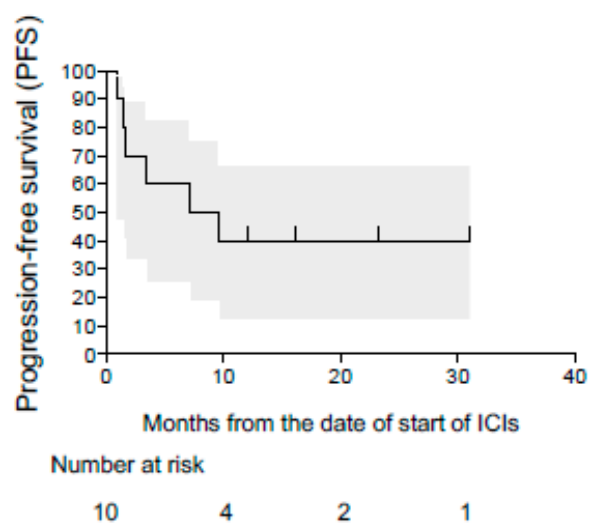

B

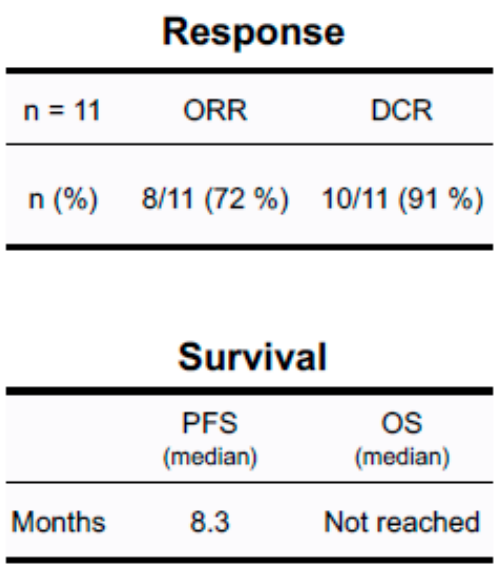

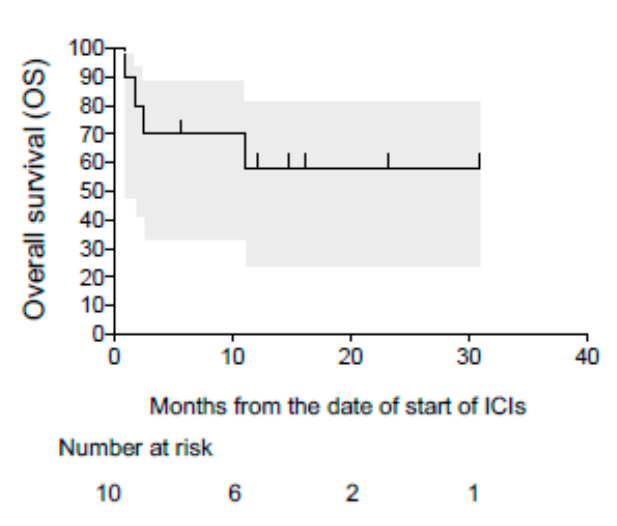

Figure 2. Association between efficacy of ICIs and the diseases associated with disorders of the coagulation-fibrinolysis system triggered by ICIs. (A) Representative immunohistochemical staining of the primary lung tumor in case 5, positive staining for programmed cell death-ligand 1 (PD-L1) (clone 22C3 pharmDx kit, tumor promotion score $\geq 75 \%$ ). Scale bar $50 \mu \mathrm{m}$. (B) Upper panel shows objective response rate (ORR) and disease control rate (DCR) in NSCLC patients who developed diseases associated with disorders of the coagulation-fibrinolysis. Lower panel shows median PFS and median OS. (C) Kaplan-Meier curves are shown for PFS and OS in those patients. Gray areas indicate $95 \%$ confidence intervals of survival.

\subsection{T Cell Activation Induce Tissue Factor Expression on PD-L1-Positive Monocytes}

LPS-activated monocytes have been known to produce abundant TF $[17,35,36]$. Consistent with the results reported previously, TF was expressed on LPS-activated CD14 ${ }^{+}$monocytes (Figure 3A,B). However, activated T cells did not express TF (Figure 3A).

Little is known about the impact of $\mathrm{T}$ cell activation on TF production in human circulating PD-L1 expressing monocytes. Thus, we next assessed the impact of activated T cells on TF expression on monocyte in vitro. To activate T cells, PBMCs from healthy donors were incubated with CD3/CD28/CD2 beads, which can provide physiological activation of human $\mathrm{T}$ cells. T cell activation was confirmed by the surface expression of CD69 and HLA-DR on $\mathrm{CD}^{+} \mathrm{T}$ cells. T cell activation by CD3/CD28/CD2 beads induced significant TF expression on $\mathrm{CD}_{1}{ }^{+}$monocytes, which was confirmed by multiparameter flow cytometric analysis and multicolor immune immunofluorescence staining (Figure 3A,B). Activated monocytes have been shown to express PD-L1 and HLA-DR on cell surface, and the PD-L1 suppresses tumor-specific $T$ cell immunity in physiological condition [37,38]. T cell activation by CD3/CD28/CD2 
beads markedly increased PD-L1 on monocytes (Figure 4A) and HLA-DR, suggesting activated T cells induced monocyte activation. Interestingly, PD-L1 $1^{\text {high }}$ monocytes expressed higher TF compared to PD-L1 ${ }^{\text {low }}$ monocytes (Figure $4 \mathrm{~B}$ ). These results suggest that $\mathrm{T}$ cell activation leads to monocyte activation and induce high TF expression on peripheral PD-L1 ${ }^{+}$monocytes.

A

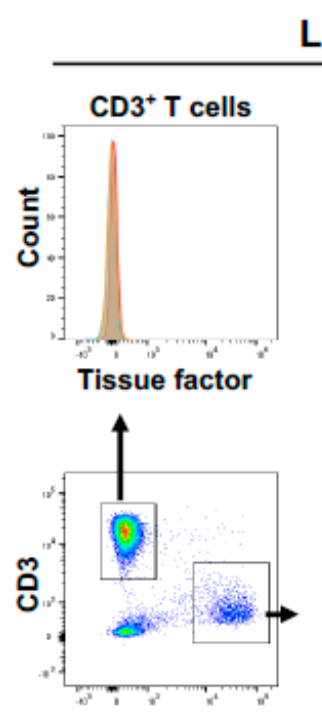

CD14

\section{LPS}
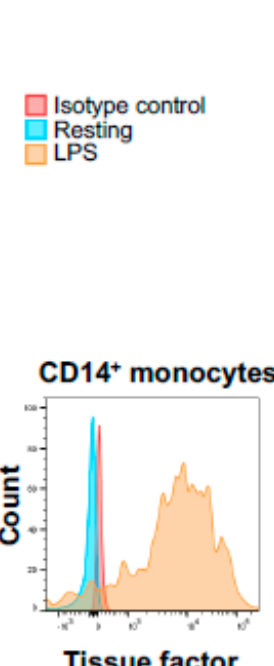

T cell activation
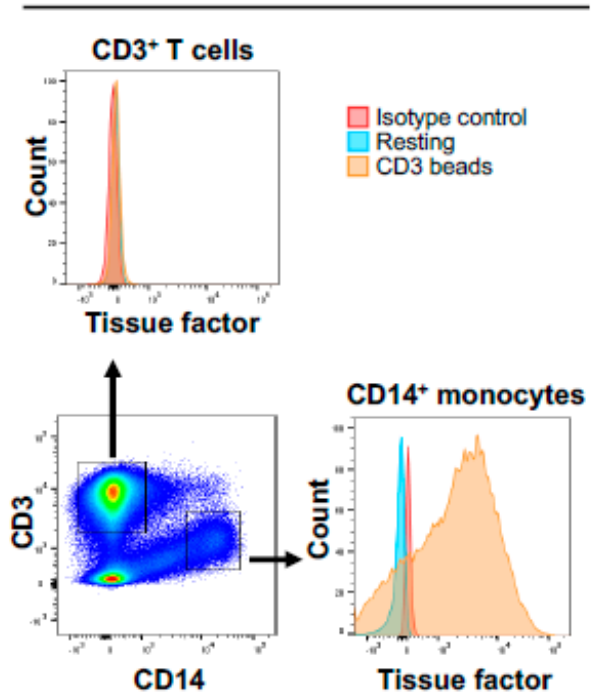

B

Resting

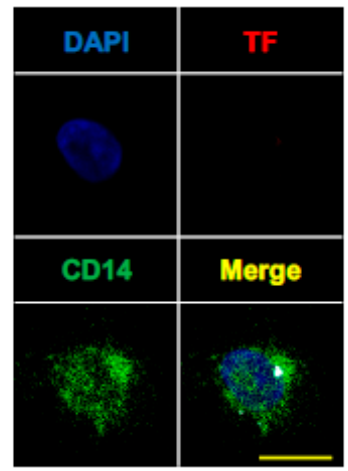

LPS

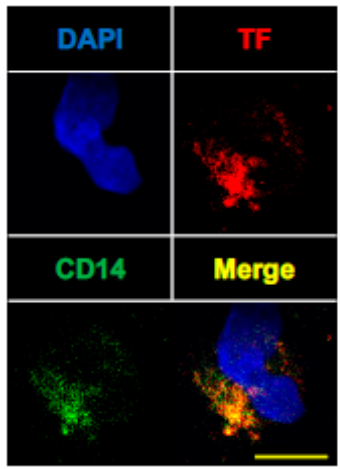

T cell activation

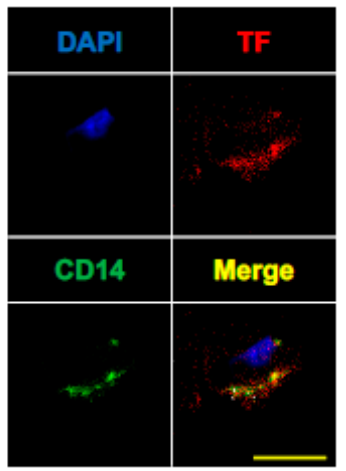

Figure 3. T cell activation induces TF expression on $\mathrm{CD}_{1} 4^{+}$monocytes. (A) Fresh PBMCs from healthy volunteers were cultured with lipopolysaccharide (LPS) to activate monocytes (left panels) or $\mathrm{CD} 3 / \mathrm{CD} 28 / \mathrm{CD} 2$ beads to activate $\mathrm{CD}^{+} \mathrm{T}$ cells (right panels). Gating strategy for analysis of $\mathrm{CD}^{+}$ $\mathrm{T}$ cells or $\mathrm{CD}_{1}{ }^{+}$monocytes is shown at each left lower panel. TF expressions were evaluated for $\mathrm{CD}^{+} \mathrm{T}$ cells and $\mathrm{CD} 14^{+}$monocytes. Representative histograms of TF on each population were shown. (B) Representative immunofluorescence images of PBMCs. Fresh PBMCs (left panels), PBMCs cultured with LPS (middle panels) or cultured with CD3/CD28/CD2 beads (right panels) were stained with antibodies against CD14 (green) and tissue factor (red). Nuclei were stained with DAPI (blue). Scale bars $10 \mu \mathrm{m}$.

Taken together, our data suggest that although, in physiological condition, upregulated PD-L1 on activated antigen-presenting cells (APCs) suppresses the activated T cells and results in end of immune activation as a homeostatic mechanism, $\mathrm{T}$ cell activation by ICIs has the potential to induce abundant TF production on APCs and may trigger disorders of the coagulation-fibrinolysis system (Figure 5) [16,17,25,36,39]. 
A

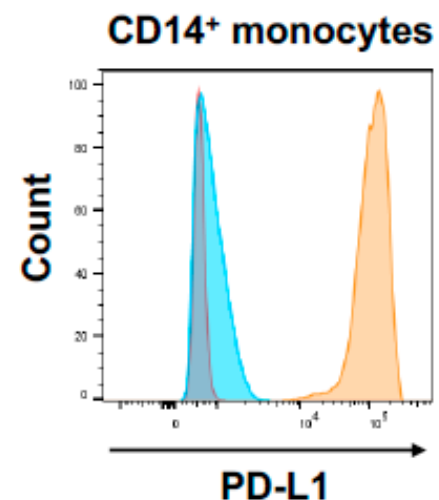

PD-L1

Isotype control

Resting
B

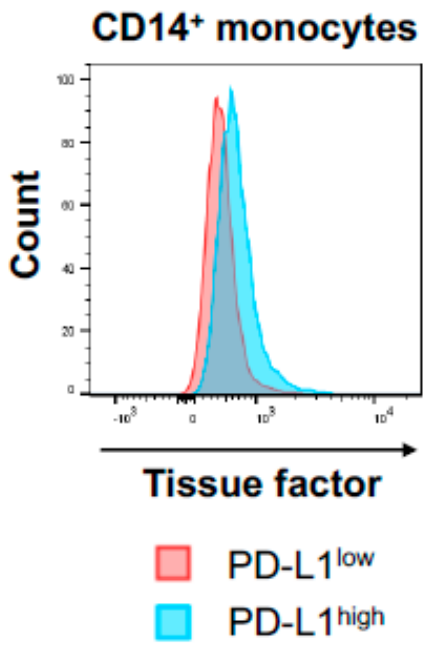

Figure 4. T cell activation increased PD-L1 on monocytes and PD-L1 ${ }^{\text {high }}$ monocytes expressed higher TF compared with PD-L1 ${ }^{\text {low }}$ monocytes. (A) Histogram of PD-L1 expression in CD14 ${ }^{+}$monocytes under resting condition or cultured with CD3/CD28/CD2 beads. (B) Histogram of TF in PD-L1 $1^{\text {high }}$ and PD-L1 ${ }^{\text {low }} \mathrm{CD}_{14}{ }^{+}$monocytes cultured with CD3/CD28/CD2 beads.

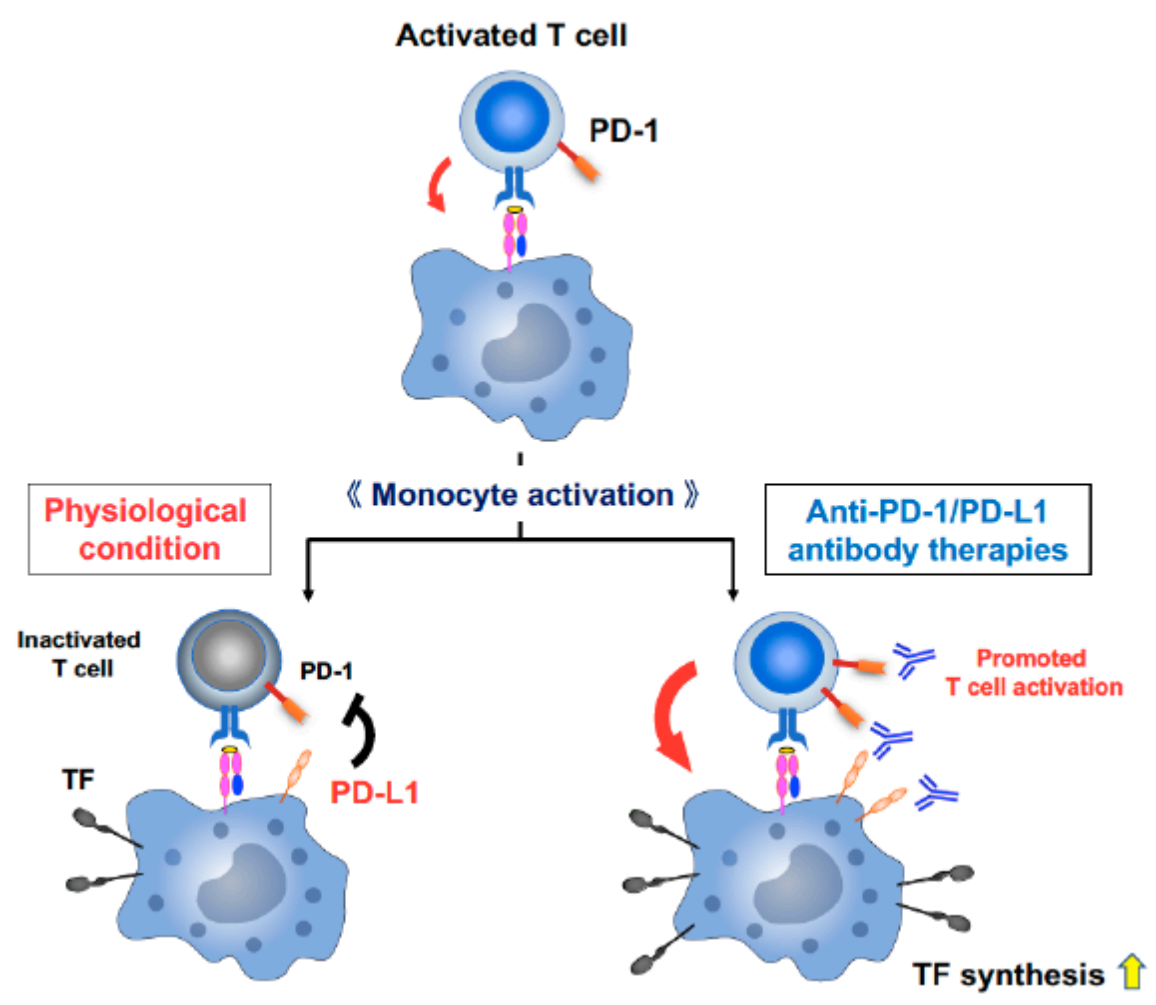

Figure 5. A model demonstrating the association between T cell activation by ICIs and TF production on APCs. T cell activation and proliferation are initiated through antigen recognition by the $\mathrm{T}$ cell receptor. The crosstalk between APCs and T cells provides crucial stimulatory signals for efficient expansion and development of effector functions to T cells and also induce activation of APCs and TF production. In physiological condition, upregulated PD-L1 on activated APCs suppresses T cells and results in end of immune activation as a homeostatic mechanism. However, ICIs provide a forced activation of T cells by blocking immune checkpoint pathways, which may lead to promoting further APC activation and abundant TF production, and may trigger disorders of the coagulation-fibrinolysis system. 


\section{Discussion}

A complex interplay between anti-PD-1/PD-L1 monoclonal antibody therapy and host immunity leads to unleash the antitumor immune response, however, the disruption of immune checkpoint signaling also leads to imbalances in immunologic tolerance resulting in an unfavorable immune response which clinically manifest as irAEs [9-14]. The number of indications for use of ICIs are growing at an unprecedented speed and ICIs have changed the clinical practice, whereas unexpected irAEs have emerged in the real-world clinical practice $[9,10,12-14]$.

In current study, we showed $12 \%$ of NSCLC patients receiving ICI monotherapies developed diseases associated with disorders of the coagulation-fibrinolysis system.

Interestingly, we found that disorders of the coagulation-fibrinolysis system occurred in patients with high PD-L1 expression on tumor cells and in the early period of ICI initiation. In addition, high tumor responses were observed including two CR cases among these patients, suggesting an association between immune activation by ICIs and the onset of disorders of the coagulation-fibrinolysis system (Table 1).

The coagulation-fibrinolysis system disorders have not been reported as irAEs in landmark clinical trials of ICIs in cancer patients. In most phase II/III clinical studies of ICIs, only AEs which were considered by the investigators to be related to the study therapy or high-incidence AEs ( $\geq 5-10 \%$ of patients who received ICI) have been reported (Table 3) [33,40-43]. Thus, not all AEs were known. AEs associated with disorders of the coagulation-fibrinolysis system have not been reported in five landmark clinical studies of ICIs in patients with advanced NSCLC, whereas hemoptysis $(n=16,6 \%)$, pulmonary embolism $(n=1,<1 \%)$ and cerebrovascular accident $(n=1,<1 \%)$ were reported in CheckMate057 [44]. However, CheckMate057 have not shown that the association of coagulation-fibrinolysis system disorder with the efficacy of ICIs.

Table 3. AEs associated with disorder of coagulation-fibrinolysis system reported in clinical trials of ICIs in patients with advanced NSCLC.

\begin{tabular}{|c|c|c|c|c|c|c|}
\hline $\begin{array}{c}\text { Study } \\
\text { [Reference] }\end{array}$ & $\begin{array}{c}\text { No. of } \\
\text { Patients Who } \\
\text { Received ICI }\end{array}$ & Phase & Histology & Treatment & $\begin{array}{l}\text { AEs Associated with } \\
\text { Disorders of } \\
\text { Coagulation- } \\
\text { Fibrinolysis System }\end{array}$ & $\begin{array}{l}\text { No. of } \\
\text { Patients (\%) }\end{array}$ \\
\hline CheckMate017 [40] & 135 & III & $\mathrm{Sq}$ & Nivolumab & \multicolumn{2}{|l|}{ Not reported * } \\
\hline \multirow{3}{*}{ CheckMate057 [44] } & \multirow{3}{*}{292} & \multirow{3}{*}{ III } & \multirow{3}{*}{$\begin{array}{l}\text { NonSq } \\
\text { NSCLC }\end{array}$} & \multirow{3}{*}{ Nivolumab } & Hemoptysis & $16(6 \%)$ \\
\hline & & & & & Pulmonary embolism & $1(<1 \%)$ \\
\hline & & & & & Cerebrovascular accident & $1(<1 \%)$ \\
\hline KEYNOTE010 [41] & 690 & II/III & NSCLC & Pembrolizumab & Not reported * & \\
\hline KEYNOTE024 [33] & 154 & III & NSCLC & Pembrolizumab & Not reported & \\
\hline OAK [43] & 425 & III & NSCLC & Atezolizumab & Not reported * & \\
\hline POPLAR [42] & 144 & II & NSCLC & Atezolizumab & Not reported * & \\
\hline
\end{tabular}

Recently, several case studies have shown that the relationship between the administration of ICIs and the occurrence of diseases associated with disorders of the coagulation-fibrinolysis system, in addition, some of the cases were severe and life-threatening, suggesting ICIs might impact coagulation-fibrinolysis system in advanced cancer patients [13,14,21-23,29]. Understanding the underling mechanisms of disorders of coagulation-fibrinolysis system caused by ICIs and clinical characteristics of the patients who develop them are urgently needed to improve their early diagnosis and develop more precise treatments for the adverse events. 


\subsection{Link between PD-L1 Expression on Tumor Cells and Efficacy of ICIs and Disorders of Coagulation-Fibrinolysis System Triggered by ICIs}

In this study, we investigated the clinical characteristics of the patients who developed diseases associated with disorders of coagulation-fibrinolysis system under treatment with ICI monotherapy. Although 5 of 18 adverse events (27\%; Table 1 ) associated with disorders of coagulation-fibrinolysis system were severe (Grade $\geq 3$ ), the ORR was $72 \%$. Furthermore, more than $90 \%$ of patients with advanced NSCLC achieved disease control. This is the first study to show benefit for patients with advanced NSCLC who developed diseases associated with disorders of the coagulation-fibrinolysis system under the treatment with ICI monotherapy.

Recent studies have shown that the association of early irAEs with the efficacy of ICIs in NSCLC, suggesting the relationship between systemic immune activation and the efficacy of ICIs [45,46]. The onset of common irAEs - such as rash, pyrexia, and endocrinopathies-have been reported to be early predictive factors of efficacy. Intriguingly, the patients who developed diseases associated with disorders of the coagulation-fibrinolysis system in association with the administration of ICIs tended to have better response to the therapy (the ORR was $72 \%$ ) in view of the recent results from clinical studies, in which ORR to ICI monotherapy or ICI combination therapies was approximately 40-60\% even in first-line setting $[30,32,33]$. In addition, the early onset of the coagulation-fibrinolysis system disorders were seen; the diseases associated with disorders of coagulation-fibrinolysis system developed within two cycles of ICI therapies for $67 \%$ patients and the median onset of cycle was one.

High PD-L1 expression on tumor cells mirrors immunologically 'hot' tumor, which are characterized by high infiltration of T cells, and the immune system in NSCLC patients with high tumor expression of PD-L1 are ready to be activated by ICIs [5,7,11]. High PD-L1 expression on tumor cells has been indeed associated with a high clinical response to ICIs in advanced NSCLC patients [32,33,47]. In addition, systemic immune activation by ICIs in peripheral blood of cancer patients have been confirmed in ICI responders $[48,49]$. In our study, all patients who developed diseases associated with disorders of coagulation-fibrinolysis system were positive for PD-L1, in addition, $82 \%$ of patients were strongly positive for PD-L1 on tumor (TPS $\geq 50 \%$ ). Importantly, activated T cells promote procoagulant activity via induction of TF in monocytes/macrophages $[16,50,51]$. We demonstrated that $\mathrm{T}$ cell activation leads to abundant TF in PD-L1 ${ }^{\text {high }} \mathrm{CD} 14^{+}$monocytes. Therefore, an association between high PD-L1 expression on tumor cells, systemic immune activation by ICIs, the response to ICIs and disorders of the coagulation-fibrinolysis system during ICI therapy potentially exists in NSCLC patients who receiving immune checkpoint blockade.

\subsection{Underlying Mechanisms of Disorders of the Coagulation-Fibrinolysis System as an irAE}

The main irAEs of ICIs are skin, lungs, thyroid, endocrine, adrenal, pituitary, gastrointestinal tract, musculoskeletal, renal, and nervous system. Little is known about the risk of vascular events associated with ICIs $[9,10]$. The hypercoagulable state in cancer involves several complex interdependent mechanisms, including interaction among cancer cells, host immune cells, and coagulation-fibrinolysis system. Key roles in pathophysiology are played by TF, inflammatory cytokines, and platelets [16-19,25,35,52-54]. TF triggers the extrinsic coagulation cascade and cause disorders of coagulation-fibrinolysis system [24,25]. Importantly, monocytes have been shown to be the major source of intravascular TF in many diseases $[16,25,27]$. Therefore, we studied the impact of $\mathrm{T}$ cell activation on TF expression on monocytes in human PBMCs. In the current study, we demonstrated that $\mathrm{T}$ cell activation lead to monocyte activation and markedly increased PD-L1 on monocytes. We showed that PD-L1 ${ }^{\text {high }}$ monocytes expressed higher TF compared to PD-L1 ${ }^{\text {low }}$ monocytes, suggesting T cell activation by anti-PD-1/PD-L1 antibodies has the potential to induce high TF expression on peripheral PD-L1+ monocytes.

The accumulating evidence suggests that activated T cells and APCs such as dendritic cells, macrophages, and monocytes are involved in provoking disorders of coagulation-fibrinolysis system [36, 39,50,51,55]. Importantly, immune checkpoint blockade not only activates $\mathrm{T}$ cells but also activates 
APCs $[37,56,57]$, indicating that anti-PD-1/PD-L1 monoclonal antibodies may trigger disorders of the coagulation-fibrinolysis system. Two possible mechanisms of the onset of diseases associated with disorders of the coagulation-fibrinolysis system under the treatment with ICIs are shown in Figure 6.

A
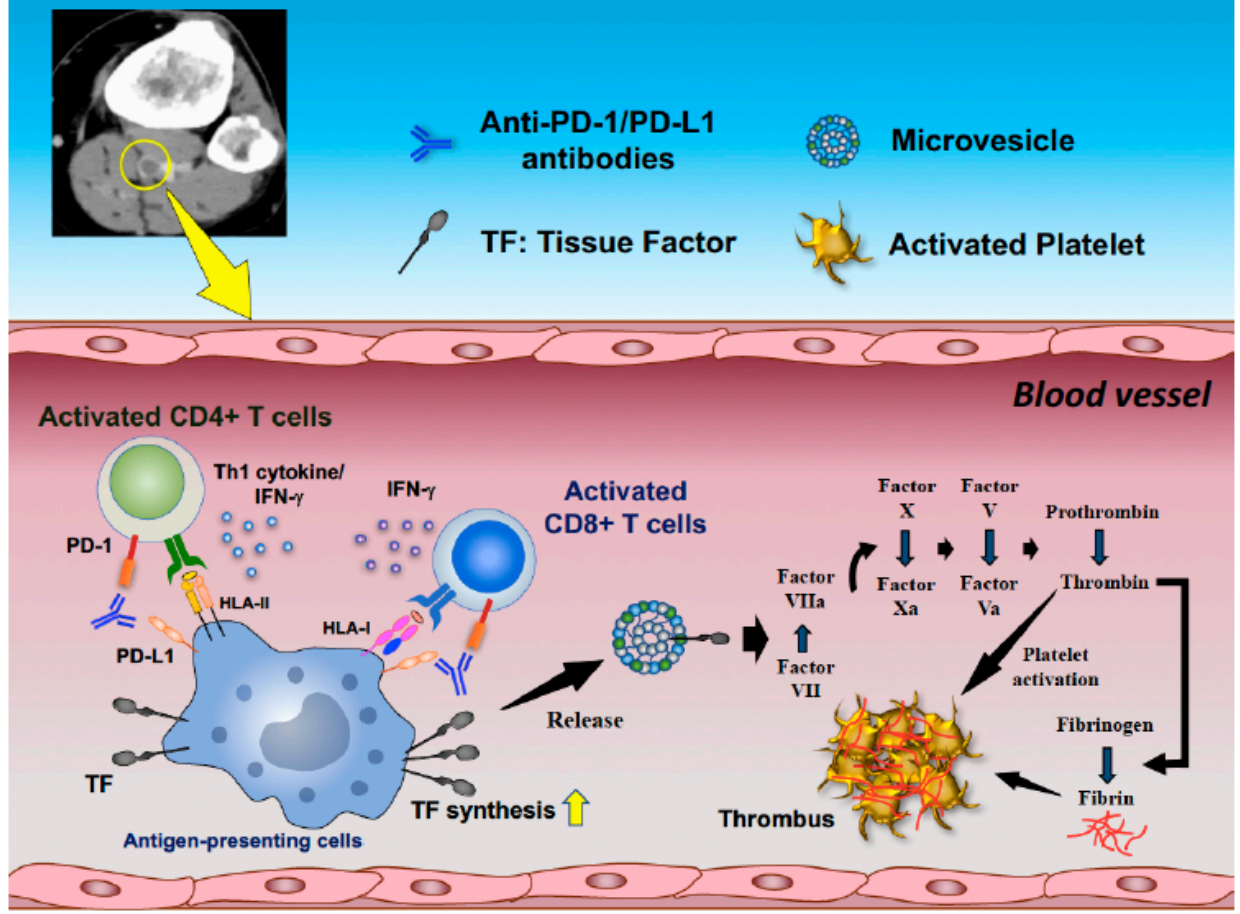

B

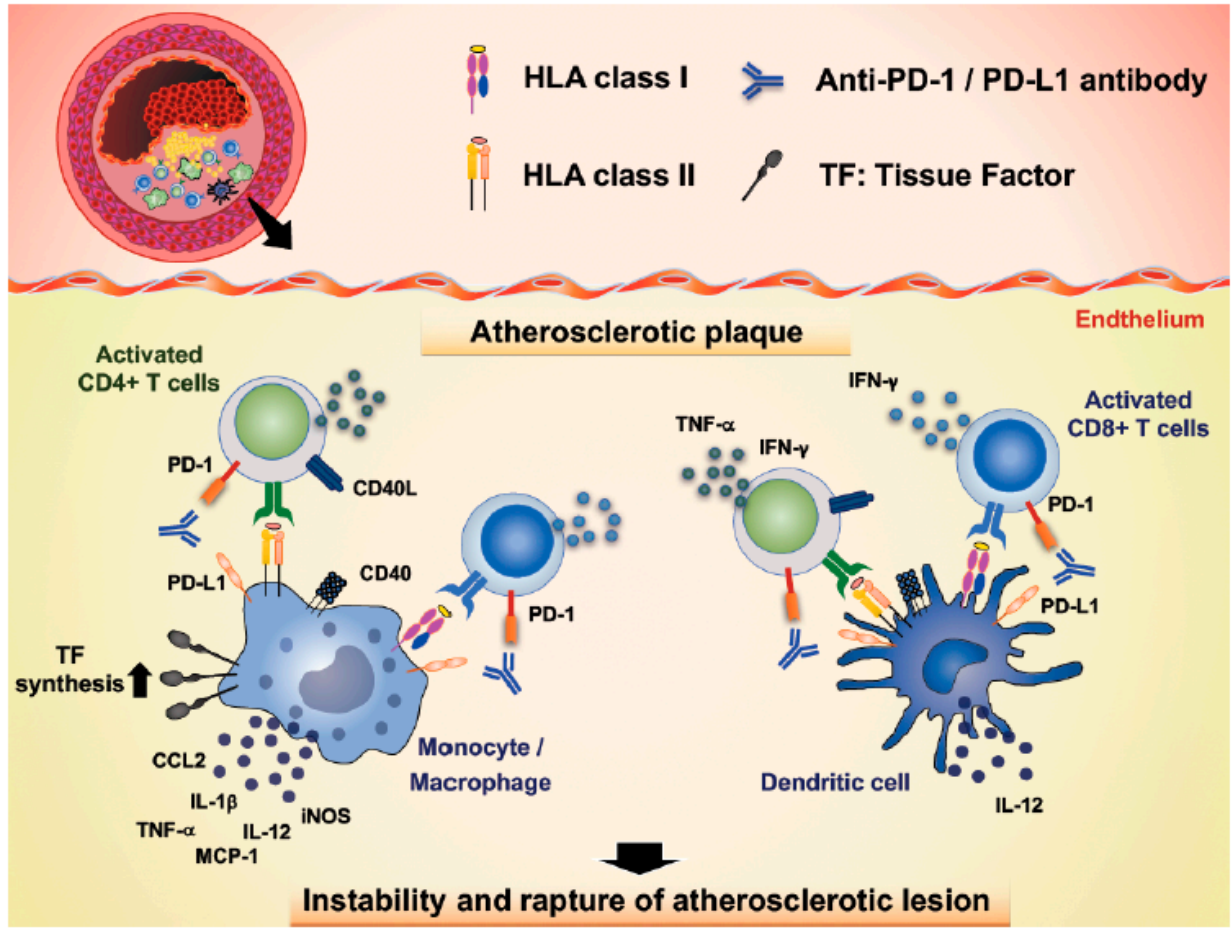

Figure 6. Hypothetical mechanisms of the onset of disorders of coagulation-fibrinolysis triggered by ICIs based on the current study and references. (A) The crosstalk between APCs and T cells provides crucial stimulatory signals for efficient expansion and development of effector functions to T cells. ICIs 
promote T cell activation by blocking the interaction between PD-1 and PD-L1 and induces IFN- $\gamma$ and Th1 cytokine production, which play a crucial role in anti-tumoral effects. In turn, the IFN- $\gamma$ and Th1 cytokines promote APC activation and TF synthesis in monocytes/macrophages. TF-containing membrane fragments or microvesicles released by the monocytes/macrophages could be a cause of distant thromboembolic events in advancer cancer patients. Microvesicles carrying TF activate factor VII. Conversion of factor VII to its active form (VIIa) in complex with TF triggers the production of other coagulation-related proteases in the coagulation cascade. The complex TF-factor VIIa converts factor $X$ to activated factor X (factor Xa). Factor Xa with its cofactor, activated factor V (factor Va), activates prothrombin and generate thrombin, which is required to transform fibrinogen into fibrin and to activate platelets. This hypothetical mechanism could play a role in intravascular thrombosis in cancer patients receiving ICIs. A contrast-enhanced CT image of leg vein from the case 9 is shown on the right upper side. (B) In atherosclerotic lesions, T cells and APCs have been shown to be involved in promoting plaque development, progression, and destabilization of atherosclerotic lesions. Activated APCs, such as monocytes/macrophages and DCs, promote inflammation by secretion of pro-inflammatory mediators such as IL-12 and TNF- $\alpha$ or by promoting T cell activation. TF expression on APCs in atherosclerotic lesions is also promoted. Activated $\mathrm{T}$ cells produce pro-atherogenic cytokines such as IFN- $\gamma$ and TNF- $\alpha$ that contribute to both the growth and destabilization of atherosclerotic lesions, which could result in rupture of the lesion. In contrast to cancer where T-cell activation and pro-inflammatory cytokines produced by immune subsets are highly appreciated, the unwanted activation of immune subsets needs to be suppressed in atherosclerotic lesions. As a homeostatic mechanism, activation of $\mathrm{T}$ cell subsets is suppressed by immune checkpoint pathways in the atherosclerotic lesions; however, ICIs could promote T-cell activation by blocking the immune checkpoint pathways. This evidence raises a hypothesis that ICIs might be involved in provoking the growth and destabilization of atherosclerotic lesions and causing disorders of coagulation-fibrinolysis by activation and recruitment of $\mathrm{T}$ cells and APCs in the atherosclerotic lesions.

There is a link between immune activation and thrombotic events within blood vessels [13, $17,35,54,55,57]$. TF is a primary initiator of fluid-phase blood coagulation and causes disorders of coagulation-fibrinolysis system $[16,17,25]$. Not only cancer cells but also activated monocytes and macrophages have been known to express abundant TF. It has been shown that monocytes/macrophages are a major source of circulating TF in the blood and their TF production is triggered by inflammatory cytokines such as IL-1 $\beta$, TNF- $\alpha$, and IFN- $\gamma$ [17]. In addition, activated T cells have been shown to promote procoagulant activity via induction of TF in monocytes/macrophages $[13,36,51]$. Thus, the accumulating evidence suggests a potential risk of triggering disorders of coagulation-fibrinolysis system in association with ICI therapy within blood vessels; T cell activation by anti-PD-1/PD-L1 monoclonal antibody therapies may lead to promoting TF synthesis in monocytes/macrophages, which could result in triggering disorders of coagulation-fibrinolysis system such as DVT, PTE, and Trousseau's syndrome in advanced cancer patients (Figure 6A).

In arteriosclerotic lesions, the activation of immune subsets including T cells and APCs-such as monocyte, macrophages, and dendritic cells-play critical roles in promoting plaque development, progression, and destabilization resulting in rupture and thrombus formation [14,39,50,52,53,58,59]. In addition, TF from activated immune subsets have been also suggested to be involved in the onset of ACS [35]. Therefore, the unwanted activation of immunity needs to be suppressed in atherosclerotic lesions. PD-1/PD-L1 signaling plays a critical role in inactivating immune cells and maintaining plaque stabilization in atherosclerotic lesions although $\mathrm{T}$ cell activation and pro-inflammatory cytokines such as interferon- $\gamma($ IFN- $\gamma)$ and TNF- $\alpha$ are highly appreciated in terms of anti-tumor effects $[14,39,50,58,60]$. Activations of both $\mathrm{CD} 4^{+} \mathrm{T}$ cells and $\mathrm{CD} 8^{+} \mathrm{T}$ cells are suppressed by immune checkpoint pathways as a homeostatic mechanism in the atherosclerotic lesions, but, immune checkpoint blockade invigorates T-cell functions and activates APCs, also suggesting a potential risk of triggering disorders of coagulation-fibrinolysis system in arteriosclerotic lesions such as ACS and cerebral infarction in association with ICI therapy (Figure 6B). 
Bleeding disorders are frequent in advanced cancer patients, and were observed in $2.7 \%$ of patients during a 1-year period [61]. Chemotherapeutic treatments have been known to heighten not only venous thromboembolism occurrence but also bleeding complications [17,62]. Although the underlying mechanism of bleeding disorders in cancer patients receiving ICI remains unclear, ICI-induced systemic immune activation followed by hypercoagulopathy and thromboembolic events consequently may cause a local consumptive coagulopathy, tissue damage, and endothelial injury could develop leading to internal and/or external bleeding complications such as purpura, intra-tumor hemorrhage, bronchial hemorrhage, and gastrointestinal hemorrhage.

Anticancer therapies have been shown to carry an increased risk of thrombotic events [19]. High rates of cancer-associated disorders of coagulation-fibrinolysis system have also been reported in cancer patients who are receiving antiangiogenic agents. In a meta-analysis of clinical trials of bevacizumab in combination with chemotherapy or interferon across a variety of cancers, the use of bevacizumab was associated with a $33 \%$ relative increase in the risk of venous thromboembolism [34]. However, the pathophysiology of anticancer therapy-associated disorders of coagulation-fibrinolysis system is not entirely understood [18-20]. Importantly, accumulating evidence from clinical and preclinical studies has shown that conventional and targeted anticancer agents have immunomodulatory or immune stimulatory effects and promote anti-tumor immunity [31,63-66], suggesting these immunomodulatory anticancer agents may also impact the coagulation-fibrinolysis system and increase the risk of thromboembolic/bleeding events through immune activation as well as ICIs.

\subsection{Targeting PD-1/PD-L1 Signaling: A Double-Edged Sword in Cancer}

A concept of "immune normalization" for the class of drugs called ICIs has recently been proposed [7]. Anti-PD-1/PD-L1 antibodies are monoclonal antibodies selectively targeting the PD-1/PD-L1 pathway and the mechanism of action of ICIs is thought to restore a lost antitumor immunity in the tumor microenvironment [7]. However, ICIs does not always change the immune balance to a favorable direction (Figure 7). ICIs selectively target the PD-1/PD-L1 pathway, however, do not selectively target the PD-1/PD-L1 signaling between tumor antigen-specific $\mathrm{T}$ cells and tumor cells, because immune cells expressing PD-1/PD-L1 not only exist in TME but also exist in peripheral blood and normal tissues, in addition, both PD-1 and PD-L1 are expressed on not only effector CD8 ${ }^{+}$ $\mathrm{T}$ cells called "killer $\mathrm{T}$ cells", but also a variety of immune cells including other T cell subsets, B cell subsets, and antigen-presenting cells including activated monocytes, macrophages, and dendritic cells $[14,37,48,49,67]$. Therefore, anti-PD-1/PD-L1 monoclonal antibodies can bind to various non tumor-specific $\mathrm{T}$ cells or non-tumor-directed immune subsets, which may lead to induce the unwanted activation of systemic immunity [59]. This may disturb the balance established between tolerance and autoimmunity and result in various irAEs.

PD-1 and PD-L1 are expressed in activated 'non tumor-specific T cells' as well as activated 'tumor-specific T cells'. Thus, immune checkpoint blockade has a potential risk of shifting the systemic immune balance from tumor-specific $T$ cell-mediated antitumor immune response to non-tumor-specific T cell-mediated immune response in cancer patients (Figures 6 and 7A).

The crosstalk between APCs and T cells plays a key role in achieving efficient anti-tumor immune responses, which can be supported by various signals derived from T cells, such as IFN- $\gamma$ [68-72]. The interaction provides crucial stimulatory signals for efficient expansion and development of effector functions to T cells (so-called "License to kill") [70,71]. APCs including monocytes and macrophages express both PD-L1 and PD-1 (Figure 7B) $[37,67]$. IFN- $\gamma$ from activated T cells not only activate APCs but also strongly induce PD-L1 expression on APCs to impede T cell function and maintain immune homeostasis, although IFN- $\gamma$ is the most important cytokine implicated in antitumor immunity [68,73]. Therefore, blocking PD-1/PD-L1 signaling can activate APCs [67,73-75] and ICIs have a potential risk of shifting the immune balance from tumor-directed monocyte/macrophage activation to non-tumor-directed monocyte/macrophage activation through $\mathrm{T}$ cell activation, resulting in common and unexpected irAEs, such as disorders of coagulation-fibrinolysis system [13-15] (Figures 5-7). In our 
current study, we demonstrated that $\mathrm{T}$ cell activation leads to monocyte activation and promotes the production of TF in PD-L1 high human peripheral CD14 ${ }^{+}$monocytes, suggesting that $\mathrm{T}$ cell activation followed by APC activation during ICI therapy may play a crucial role in triggering the diseases associated with disorders of the coagulation-fibrinolysis system.

A

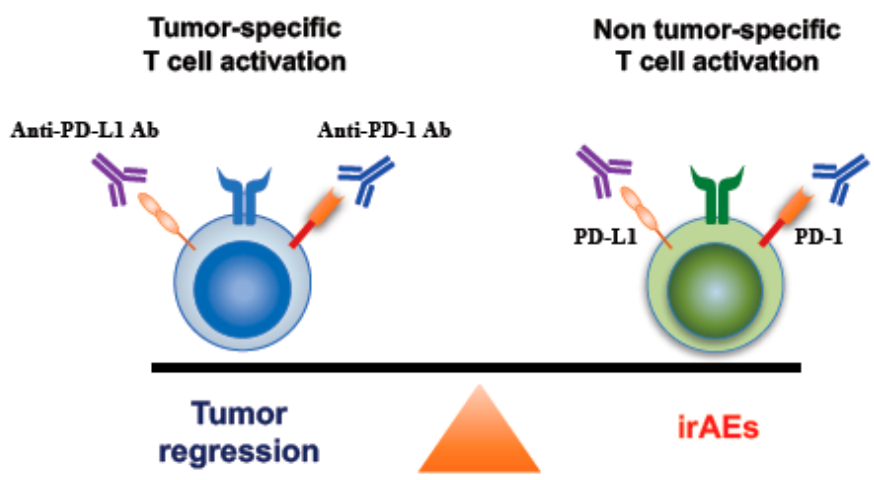

B

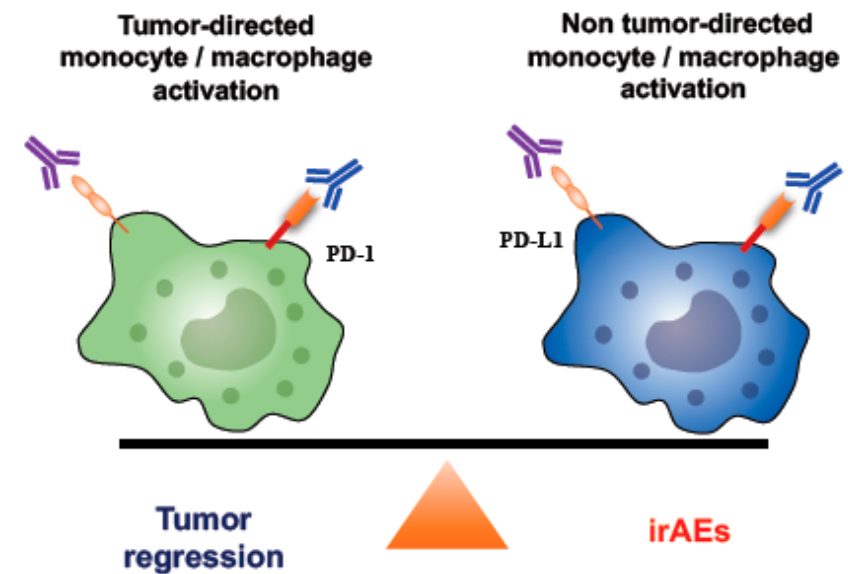

Figure 7. Underlying mechanisms of irAEs caused by activated T cells and monocytes/macrophages. (A) A model of immune balance between tumor-specific and non-tumor-specific T cells. ICIs can activate not only tumor-specific $\mathrm{T}$ cells but also non-tumor-specific $\mathrm{T}$ cells. Thus, ICIs have the potential to modulate the balance between tumor-specific $\mathrm{T}$ cell response and non-tumor-specific $\mathrm{T}$ cell response. PD-1/PD-L1 express on both tumor-specific and non-tumor-specific $\mathrm{T}$ cells. If non tumor-specific T cells are dominantly activated by ICIs, this may lead to the onset of irAEs. (B) A model of immune balance between tumor-directed monocyte/macrophage activation and non-tumor-directed monocyte/macrophage activation. PD-1/PD-L1 express on both tumor-directed and non-tumor-directed monocytes/macrophages. Thus, ICIs could activate both tumor-directed and non-tumor-directed monocytes/macrophages and have the potential to modulate the immune balance. If non tumor-directed monocytes/macrophages are dominantly activated by ICIs, this may lead to the onset of irAEs such as disorders of the coagulation-fibrinolysis system.

\subsection{Limitation}

Our findings should be interpreted with caution in view of the limited samples, retrospective study, short observation period, and heterogeneity of study cohort (ICIs used in this study and prior lines of therapy); the results need to be confirmed in larger cohorts. Because the cancer-associated thromboembolic and bleeding events are common in advanced cancer patients and 
diverse asymptomatic disorders are present in single patients [18-20], it is conceivable that disorders of the coagulation-fibrinolysis system during ICI therapy could be unrecognized by clinicians and real incidence of the diseases associated with disorders of the coagulation-fibrinolysis system might be higher than that of our study. The cause-and-effect relationship between ICI and disorders of the coagulation-fibrinolysis system is not completely proven, although we showed $\mathrm{T}$ cell activation leads to promote production of TF in PD-L1 ${ }^{+}$monocytes in vitro. In our current study, we showed TF expression on monocytes, however, TF can also be induced in the endothelial cells of the vessel wall and smooth muscle cells under various pathologic conditions, and tumor cells also express abundant TF. Thus, various mechanisms of TF production should be considered in cancer patients receiving ICI therapy. Inflammatory cytokines derived from activated immune subsets by ICI have the potential to play a key role in pathophysiology of disorders of the coagulation-fibrinolysis system. Excessive inflammatory cytokines may induce tissue damage and endothelial injury, which could lead to TF production from various tissues. TF release from tumor cells killed by activated $\mathrm{T}$ cells may also trigger disorders of the coagulation-fibrinolysis system. Further studies including monitoring TF expression on circulating monocytes in cancer patients receiving ICI monotherapy are needed to unveil the mechanism of thromboembolic and bleeding complications in cancer immunotherapy.

\section{Conclusions}

This is the first evidence suggesting the association between disorders of the coagulationfibrinolysis system and immune activation by ICIs in cancer patients with PD-L1 ${ }^{+}$tumor. The present study may contribute to our understanding of the mechanism of disorders of the coagulation-fibrinolysis system in cancer patients and provide new insights into the complex interplay among cancer, host-immunity, and immunotherapy.

Author Contributions: Conception and design: R.S., K.I., S.S. (Shinya Sakata), T.I., K.S., and Y.T.; Acquisition of clinical data and patient care: R.S., S.S. (Shinya Sakata), Y.H., S.I. (Shinji Iyama), K.A., S.H., T.J., K.N., S.I. (Shiho Ishizuka), K.S., S.S. (Sho Saeki), T.S., and Y.T.; Analysis and interpretation of biological data: R.S., K.I., S.S. (Shinya Sakata), K.S., N.S., S.S. (Sho Saeki), T.S., and Y.T.; Writing, review, and/or revision of the manuscript: R.S., K.I., S.S. (Shinya Sakata), T.I., K.S., S.S. (Sho Saeki), T.S., and Y.T.; Study supervision: R.S., T.I., K.S., S.S. (Sho Saeki), T.S., and Y.T.

Funding: This work was supported by Takeda Science Foundation and JSPS KAKENHI grant number JP18K15928.

Acknowledgments: We thank Misako Takahashi (Department of Respiratory Medicine, Kumamoto University) for technical assistance in vitro analysis. We are very grateful to our patients for participation in this study.

Conflicts of Interest: The authors declare no conflict of interest.

\section{References}

1. Pardoll, D.M. The blockade of immune checkpoints in cancer immunotherapy. Nat. Rev. Cancer 2012, 12, 252-264. [CrossRef]

2. Schreiber, R.D.; Old, L.J.; Smyth, M.J. Cancer immunoediting: Integrating immunity's roles in cancer suppression and promotion. Science 2011, 331, 1565-1570. [CrossRef]

3. Sharma, P.; Hu-Lieskovan, S.; Wargo, J.A.; Ribas, A. Primary, Adaptive, and Acquired Resistance to Cancer Immunotherapy. Cell 2017, 168, 707-723. [CrossRef] [PubMed]

4. Zindl, C.L.; Chaplin, D.D. Immunology. Tumor immune evasion. Science 2010, 328, 697-698. [CrossRef] [PubMed]

5. $\quad$ Binnewies, M.; Roberts, E.W.; Kersten, K.; Chan, V.; Fearon, D.F.; Merad, M.; Coussens, L.M.; Gabrilovich, D.I.; Ostrand-Rosenberg, S.; Hedrick, C.C.; et al. Understanding the tumor immune microenvironment (TIME) for effective therapy. Nat. Med. 2018, 24, 541-550. [CrossRef] [PubMed]

6. Riley, R.S.; June, C.H.; Langer, R.; Mitchell, M.J. Delivery technologies for cancer immunotherapy. Nat. Rev. Drug Discov. 2019, 18, 175-196. [CrossRef]

7. Sanmamed, M.F.; Chen, L. A Paradigm Shift in Cancer Immunotherapy: From Enhancement to Normalization. Cell 2018, 175, 313-326. [CrossRef] 
8. Dugger, S.A.; Platt, A.; Goldstein, D.B. Drug development in the era of precision medicine. Nat. Rev. Drug Discov. 2018, 17, 183-196. [CrossRef] [PubMed]

9. Postow, M.A.; Sidlow, R.; Hellmann, M.D. Immune-Related Adverse Events Associated with Immune Checkpoint Blockade. N. Engl. J. Med. 2018, 378, 158-168. [CrossRef]

10. Brahmer, J.R.; Lacchetti, C.; Schneider, B.J.; Atkins, M.B.; Brassil, K.J.; Caterino, J.M.; Chau, I.; Ernstoff, M.S.; Gardner, J.M.; Ginex, P.; et al. Management of Immune-Related Adverse Events in Patients Treated With Immune Checkpoint Inhibitor Therapy: American Society of Clinical Oncology Clinical Practice Guideline. J. Clin. Oncol. 2018, 36, 1714-1768. [CrossRef]

11. Saruwatari, K.; Sato, R.; Nakane, S.; Sakata, S.; Takamatsu, K.; Jodai, T.; Mito, R.; Horio, Y.; Saeki, S.; Tomita, Y.; et al. The Risks and Benefits of Immune Checkpoint Blockade in Anti-AChR Antibody-Seropositive Non-Small Cell Lung Cancer Patients. Cancers 2019, 11, 140. [CrossRef] [PubMed]

12. Jodai, T.; Yoshida, C.; Sato, R.; Kakiuchi, Y.; Sato, N.; Iyama, S.; Kimura, T.; Saruwatari, K.; Saeki, S.; Ichiyasu, H.; et al. A potential mechanism of the onset of acute eosinophilic pneumonia triggered by an anti-PD-1 immune checkpoint antibody in a lung cancer patient. Immun. Inflamm. Dis. 2018, 7, 3-6. [CrossRef] [PubMed]

13. Horio, Y.; Takamatsu, K.; Tamanoi, D.; Sato, R.; Saruwatari, K.; Ikeda, T.; Nakane, S.; Nakajima, M.; Saeki, S.; Ichiyasu, H.; et al. Trousseau's syndrome triggered by an immune checkpoint blockade in a non-small cell lung cancer patient. Eur. J. Immunol. 2018, 48, 1764-1767. [CrossRef] [PubMed]

14. Tomita, Y.; Sueta, D.; Kakiuchi, Y.; Saeki, S.; Saruwatari, K.; Sakata, S.; Jodai, T.; Migiyama, Y.; Akaike, K.; Hirosako, S.; et al. Acute coronary syndrome as a possible immune-related adverse event in a lung cancer patient achieving a complete response to anti-PD-1 immune checkpoint antibody. Ann. Oncol. 2017, 28, 2893-2895. [CrossRef]

15. Malissen, N.; Lacotte, J.; Du-Thanh, A.; Gaudy-Marqueste, C.; Guillot, B.; Grob, J.J. Macrophage activation syndrome: A new complication of checkpoint inhibitors. Eur. J. Cancer 2017, 77, 88-89. [CrossRef]

16. Varki, A. Trousseau's syndrome: Multiple definitions and multiple mechanisms. Blood 2007, 110, $1723-1729$. [CrossRef]

17. Repetto, O.; De Re, V. Coagulation and fibrinolysis in gastric cancer. Ann. N. Y. Acad. Sci. 2017, 1404, $27-48$. [CrossRef]

18. Petrelli, F.; Cabiddu, M.; Borgonovo, K.; Barni, S. Risk of venous and arterial thromboembolic events associated with anti-EGFR agents: A meta-analysis of randomized clinical trials. Ann. Oncol. 2012, 23, 1672-1679. [CrossRef]

19. Khorana, A.A. Cancer and thrombosis: Implications of published guidelines for clinical practice. Ann. Oncol. 2009, 20, 1619-1630. [CrossRef]

20. Qi, W.X.; Shen, Z.; Tang, L.N.; Yao, Y. Risk of arterial thromboembolic events with vascular endothelial growth factor receptor tyrosine kinase inhibitors: An up-to-date meta-analysis. Crit. Rev. Oncol. Hematol. 2014, 92, 71-82. [CrossRef] [PubMed]

21. Boutros, C.; Scoazec, J.Y.; Mateus, C.; Routier, E.; Roy, S.; Robert, C. Arterial thrombosis and anti-PD-1 blockade. Eur. J. Cancer 2018, 91, 164-166. [CrossRef] [PubMed]

22. Ferreira, M.; Pichon, E.; Carmier, D.; Bouquet, E.; Pageot, C.; Bejan-Angoulvant, T.; Campana, M.; Vermes, E.; Marchand-Adam, S. Coronary Toxicities of Anti-PD-1 and Anti-PD-L1 Immunotherapies: A Case Report and Review of the Literature and International Registries. Target. Oncol. 2018, 13, 509-515. [CrossRef] [PubMed]

23. Ikeda, T.; Yamaguchi, H.; Dotsu, Y.; Taniguchi, H.; Gyoutoku, H.; Senju, H.; Sakamoto, N.; Iwanaga, S.; Kuwatsuka, Y.; Fukuda, M.; et al. Diffuse alveolar hemorrhage with pseudoprogression during nivolumab therapy in a patient with malignant melanoma. Thorac. Cancer 2018, 9, 1522-1524. [CrossRef] [PubMed]

24. Mackman, N. Role of tissue factor in hemostasis, thrombosis, and vascular development. Arterioscler. Thromb. Vasc. Biol. 2004, 24, 1015-1022. [CrossRef] [PubMed]

25. Kasthuri, R.S.; Taubman, M.B.; Mackman, N. Role of tissue factor in cancer. J. Clin. Oncol. 2009, 27, 4834-4838. [CrossRef]

26. Morel, O.; Toti, F.; Hugel, B.; Bakouboula, B.; Camoin-Jau, L.; Dignat-George, F.; Freyssinet, J.M. Procoagulant microparticles: Disrupting the vascular homeostasis equation? Arterioscler. Thromb. Vasc. Biol. 2006, 26, 2594-2604. [CrossRef]

27. Gregory, S.A.; Morrissey, J.H.; Edgington, T.S. Regulation of tissue factor gene expression in the monocyte procoagulant response to endotoxin. Mol. Cell. Biol. 1989, 9, 2752-2755. [CrossRef] 
28. Delanoy, N.; Michot, J.M.; Comont, T.; Kramkimel, N.; Lazarovici, J.; Dupont, R.; Champiat, S.; Chahine, C.; Robert, C.; Herbaux, C.; et al. Haematological immune-related adverse events induced by anti-PD-1 or anti-PD-L1 immunotherapy: A descriptive observational study. Lancet Haematol. 2019, 6, e48-e57. [CrossRef]

29. Kunimasa, K.; Nishino, K.; Kimura, M.; Inoue, T.; Tamiya, M.; Kumagai, T.; Imamura, F. Pembrolizumabinduced acute thrombosis: A case report. Medicine 2018, 97, e10772. [CrossRef]

30. Carbone, D.P.; Reck, M.; Paz-Ares, L.; Creelan, B.; Horn, L.; Steins, M.; Felip, E.; van den Heuvel, M.M.; Ciuleanu, T.E.; Badin, F.; et al. First-Line Nivolumab in Stage IV or Recurrent Non-Small-Cell Lung Cancer. N. Engl. J. Med. 2017, 376, 2415-2426. [CrossRef] [PubMed]

31. Gandhi, L.; Rodriguez-Abreu, D.; Gadgeel, S.; Esteban, E.; Felip, E.; De Angelis, F.; Domine, M.; Clingan, P.; Hochmair, M.J.; Powell, S.F.; et al. Pembrolizumab plus Chemotherapy in Metastatic Non-Small-Cell Lung Cancer. N. Engl. J. Med. 2018, 378, 2078-2092. [CrossRef]

32. Mok, T.S.K.; Wu, Y.L.; Kudaba, I.; Kowalski, D.M.; Cho, B.C.; Turna, H.Z.; Castro, G., Jr.; Srimuninnimit, V.; Laktionov, K.K.; Bondarenko, I.; et al. Pembrolizumab versus chemotherapy for previously untreated, PD-L1-expressing, locally advanced or metastatic non-small-cell lung cancer (KEYNOTE-042): A randomised, open-label, controlled, phase 3 trial. Lancet 2019, 393, 1819-1830. [CrossRef]

33. Reck, M.; Rodriguez-Abreu, D.; Robinson, A.G.; Hui, R.; Csoszi, T.; Fulop, A.; Gottfried, M.; Peled, N.; Tafreshi, A.; Cuffe, S.; et al. Pembrolizumab versus Chemotherapy for PD-L1-Positive Non-Small-Cell Lung Cancer. N. Engl. J. Med. 2016, 375, 1823-1833. [CrossRef] [PubMed]

34. Nalluri, S.R.; Chu, D.; Keresztes, R.; Zhu, X.; Wu, S. Risk of venous thromboembolism with the angiogenesis inhibitor bevacizumab in cancer patients: A meta-analysis. JAMA 2008, 300, 2277-2285. [CrossRef]

35. De Palma, R.; Cirillo, P.; Ciccarelli, G.; Barra, G.; Conte, S.; Pellegrino, G.; Pasquale, G.; Nassa, G.; Pacifico, F.; Leonardi, A.; et al. Expression of functional tissue factor in activated T-lymphocytes in vitro and in vivo: A possible contribution of immunity to thrombosis? Int. J. Cardiol. 2016, 218, 188-195. [CrossRef]

36. Peshkova, A.D.; Le Minh, G.; Tutwiler, V.; Andrianova, I.A.; Weisel, J.W.; Litvinov, R.I. Activated Monocytes Enhance Platelet-Driven Contraction of Blood Clots via Tissue Factor Expression. Sci. Rep. 2017, 7, 5149. [CrossRef]

37. Francisco, L.M.; Sage, P.T.; Sharpe, A.H. The PD-1 pathway in tolerance and autoimmunity. Immunol. Rev. 2010, 236, 219-242. [CrossRef]

38. Kuang, D.M.; Zhao, Q.; Peng, C.; Xu, J.; Zhang, J.P.; Wu, C.; Zheng, L. Activated monocytes in peritumoral stroma of hepatocellular carcinoma foster immune privilege and disease progression through PD-L1. J. Exp. Med. 2009, 206, 1327-1337. [CrossRef] [PubMed]

39. Tabas, I.; Lichtman, A.H. Monocyte-Macrophages and T Cells in Atherosclerosis. Immunity 2017, 47, 621-634. [CrossRef]

40. Brahmer, J.; Reckamp, K.L.; Baas, P.; Crino, L.; Eberhardt, W.E.; Poddubskaya, E.; Antonia, S.; Pluzanski, A.; Vokes, E.E.; Holgado, E.; et al. Nivolumab versus Docetaxel in Advanced Squamous-Cell Non-Small-Cell Lung Cancer. N. Engl. J. Med. 2015, 373, 123-135. [CrossRef]

41. Herbst, R.S.; Baas, P.; Kim, D.W.; Felip, E.; Perez-Gracia, J.L.; Han, J.Y.; Molina, J.; Kim, J.H.; Arvis, C.D.; Ahn, M.J.; et al. Pembrolizumab versus docetaxel for previously treated, PD-L1-positive, advanced non-small-cell lung cancer (KEYNOTE-010): A randomised controlled trial. Lancet 2016, 387, 1540-1550. [CrossRef]

42. Fehrenbacher, L.; Spira, A.; Ballinger, M.; Kowanetz, M.; Vansteenkiste, J.; Mazieres, J.; Park, K.; Smith, D.; Artal-Cortes, A.; Lewanski, C.; et al. Atezolizumab versus docetaxel for patients with previously treated non-small-cell lung cancer (POPLAR): A multicentre, open-label, phase 2 randomised controlled trial. Lancet 2016, 387, 1837-1846. [CrossRef]

43. Rittmeyer, A.; Barlesi, F.; Waterkamp, D.; Park, K.; Ciardiello, F.; von Pawel, J.; Gadgeel, S.M.; Hida, T.; Kowalski, D.M.; Dols, M.C.; et al. Atezolizumab versus docetaxel in patients with previously treated non-small-cell lung cancer (OAK): A phase 3, open-label, multicentre randomised controlled trial. Lancet 2017, 389, 255-265. [CrossRef]

44. Borghaei, H.; Paz-Ares, L.; Horn, L.; Spigel, D.R.; Steins, M.; Ready, N.E.; Chow, L.Q.; Vokes, E.E.; Felip, E.; Holgado, E.; et al. Nivolumab versus Docetaxel in Advanced Nonsquamous Non-Small-Cell Lung Cancer. N. Engl. J. Med. 2015, 373, 1627-1639. [CrossRef] 
45. Reck, M.; Rodriguez-Abreu, D.; Robinson, A.G.; Hui, R.; Csoszi, T.; Fulop, A.; Gottfried, M.; Peled, N.; Tafreshi, A.; Cuffe, S.; et al. Updated Analysis of KEYNOTE-024: Pembrolizumab Versus Platinum-Based Chemotherapy for Advanced Non-Small-Cell Lung Cancer With PD-L1 Tumor Proportion Score of 50\% or Greater. J. Clin. Oncol. 2019, 37, 537-546. [CrossRef]

46. Kamphorst, A.O.; Pillai, R.N.; Yang, S.; Nasti, T.H.; Akondy, R.S.; Wieland, A.; Sica, G.L.; Yu, K.; Koenig, L.; Patel, N.T.; et al. Proliferation of PD-1+ CD8 T cells in peripheral blood after PD-1-targeted therapy in lung cancer patients. Proc. Natl. Acad. Sci. USA 2017, 114, 4993-4998. [CrossRef]

47. Kamphorst, A.O.; Wieland, A.; Nasti, T.; Yang, S.; Zhang, R.; Barber, D.L.; Konieczny, B.T.; Daugherty, C.Z.; Koenig, L.; Yu, K.; et al. Rescue of exhausted CD8 T cells by PD-1-targeted therapies is CD28-dependent. Science 2017, 355, 1423-1427. [CrossRef]

48. Foks, A.C.; Kuiper, J. Immune checkpoint proteins: Exploring their therapeutic potential to regulate atherosclerosis. Br. J. Pharmacol. 2017, 174, 3940-3955. [CrossRef]

49. Del Prete, G.; De Carli, M.; Lammel, R.M.; D’Elios, M.M.; Daniel, K.C.; Giusti, B.; Abbate, R.; Romagnani, S. Th1 and Th2 T-helper cells exert opposite regulatory effects on procoagulant activity and tissue factor production by human monocytes. Blood 1995, 86, 250-257.

50. Teraoka, S.; Fujimoto, D.; Morimoto, T.; Kawachi, H.; Ito, M.; Sato, Y.; Nagata, K.; Nakagawa, A.; Otsuka, K.; Uehara, K.; et al. Early Immune-Related Adverse Events and Association with Outcome in Advanced Non-Small Cell Lung Cancer Patients Treated with Nivolumab: A Prospective Cohort Study. J. Thorac. Oncol. 2017, 12, 1798-1805. [CrossRef]

51. Haratani, K.; Hayashi, H.; Chiba, Y.; Kudo, K.; Yonesaka, K.; Kato, R.; Kaneda, H.; Hasegawa, Y.; Tanaka, K.; Takeda, M.; et al. Association of Immune-Related Adverse Events With Nivolumab Efficacy in Non-Small-Cell Lung Cancer. JAMA Oncol. 2018, 4, 374-378. [CrossRef]

52. Bu, D.X.; Tarrio, M.; Maganto-Garcia, E.; Stavrakis, G.; Tajima, G.; Lederer, J.; Jarolim, P.; Freeman, G.J.; Sharpe, A.H.; Lichtman, A.H. Impairment of the programmed cell death-1 pathway increases atherosclerotic lesion development and inflammation. Arterioscler. Thromb. Vasc. Biol. 2011, 31, 1100-1107. [CrossRef]

53. Grabie, N.; Lichtman, A.H.; Padera, R. T cell checkpoint regulators in the heart. Cardiovasc. Res. 2019, 115, 869-877. [CrossRef]

54. Khaspekova, S.G.; Antonova, O.A.; Shustova, O.N.; Yakushkin, V.V.; Golubeva, N.V.; Titaeva, E.V.; Dobrovolsky, A.B.; Mazurov, A.V. Activity of Tissue Factor in Microparticles Produced in vitro by Endothelial Cells, Monocytes, Granulocytes, and Platelets. Biochemistry 2016, 81, 114-121. [CrossRef]

55. Wakefield, T.W.; Myers, D.D.; Henke, P.K. Mechanisms of venous thrombosis and resolution. Arterioscler. Thromb. Vasc. Biol. 2008, 28, 387-391. [CrossRef]

56. Summers deLuca, L.; Gommerman, J.L. Fine-tuning of dendritic cell biology by the TNF superfamily. Nat. Rev. Immunol. 2012, 12, 339-351. [CrossRef]

57. Ivanova, E.A.; Orekhov, A.N. Monocyte Activation in Immunopathology: Cellular Test for Development of Diagnostics and Therapy. J. Immunol. Res. 2016, 2016, 4789279. [CrossRef]

58. Srikanth, S.; Ambrose, J.A. Pathophysiology of coronary thrombus formation and adverse consequences of thrombus during PCI. Curr. Cardiol. Rev. 2012, 8, 168-176. [CrossRef]

59. Simons, K.H.; de Jong, A.; Jukema, J.W.; de Vries, M.R.; Arens, R.; Quax, P.H.A. T cell co-stimulation and co-inhibition in cardiovascular disease: A double-edged sword. Nat. Rev. Cardiol. 2019, 16, 325-343. [CrossRef]

60. Rushworth, S.A.; Shah, S.; MacEwan, D.J. TNF mediates the sustained activation of Nrf2 in human monocytes. J. Immunol. 2011, 187, 702-707. [CrossRef]

61. Kakkar, A.K.; Levine, M.N.; Kadziola, Z.; Lemoine, N.R.; Low, V.; Patel, H.K.; Rustin, G.; Thomas, M.; Quigley, M.; Williamson, R.C. Low molecular weight heparin, therapy with dalteparin, and survival in advanced cancer: The fragmin advanced malignancy outcome study (FAMOUS). J. Clin. Oncol. 2004, 22, 1944-1948. [CrossRef]

62. Lyman, G.H.; Eckert, L.; Wang, Y.; Wang, H.; Cohen, A. Venous thromboembolism risk in patients with cancer receiving chemotherapy: A real-world analysis. Oncologist 2013, 18, 1321-1329. [CrossRef]

63. Galluzzi, L.; Senovilla, L.; Zitvogel, L.; Kroemer, G. The secret ally: Immunostimulation by anticancer drugs. Nat. Rev. Drug Discov. 2012, 11, 215-233. [CrossRef]

64. Galluzzi, L.; Buque, A.; Kepp, O.; Zitvogel, L.; Kroemer, G. Immunogenic cell death in cancer and infectious disease. Nat. Rev. Immunol. 2017, 17, 97-111. [CrossRef] 
65. Paz-Ares, L.; Luft, A.; Vicente, D.; Tafreshi, A.; Gumus, M.; Mazieres, J.; Hermes, B.; Cay Senler, F.; Csoszi, T.; Fulop, A.; et al. Pembrolizumab plus Chemotherapy for Squamous Non-Small-Cell Lung Cancer. N. Engl. J. Med. 2018, 379, 2040-2051. [CrossRef]

66. Socinski, M.A.; Jotte, R.M.; Cappuzzo, F.; Orlandi, F.; Stroyakovskiy, D.; Nogami, N.; Rodriguez-Abreu, D.; Moro-Sibilot, D.; Thomas, C.A.; Barlesi, F.; et al. Atezolizumab for First-Line Treatment of Metastatic Nonsquamous NSCLC. N. Engl. J. Med. 2018, 378, 2288-2301. [CrossRef]

67. Gordon, S.R.; Maute, R.L.; Dulken, B.W.; Hutter, G.; George, B.M.; McCracken, M.N.; Gupta, R.; Tsai, J.M.; Sinha, R.; Corey, D.; et al. PD-1 expression by tumour-associated macrophages inhibits phagocytosis and tumour immunity. Nature 2017, 545, 495-499. [CrossRef]

68. Jakubzick, C.V.; Randolph, G.J.; Henson, P.M. Monocyte differentiation and antigen-presenting functions. Nat. Rev. Immunol. 2017, 17, 349-362. [CrossRef]

69. Underhill, D.M.; Bassetti, M.; Rudensky, A.; Aderem, A. Dynamic interactions of macrophages with T cells during antigen presentation. J. Exp. Med. 1999, 190, 1909-1914. [CrossRef]

70. Melief, C.J. "License to kill” reflects joint action of CD4 and CD8 T cells. Clin. Cancer Res. 2013, 19, 4295-4296. [CrossRef]

71. Tomita, Y.; Yuno, A.; Tsukamoto, H.; Senju, S.; Kuroda, Y.; Hirayama, M.; Irie, A.; Kawahara, K.; Yatsuda, J.; Hamada, A.; et al. Identification of promiscuous KIF20A long peptides bearing both CD4+ and CD8+ T-cell epitopes: KIF20A-specific CD4+ T-cell immunity in patients with malignant tumor. Clin. Cancer Res. 2013, 19, 4508-4520. [CrossRef]

72. Ahrends, T.; Spanjaard, A.; Pilzecker, B.; Babala, N.; Bovens, A.; Xiao, Y.; Jacobs, H.; Borst, J. CD4(+) T Cell Help Confers a Cytotoxic T Cell Effector Program Including Coinhibitory Receptor Downregulation and Increased Tissue Invasiveness. Immunity 2017, 47, 848-861.e845. [CrossRef]

73. Gao, Y.; Yang, J.; Cai, Y.; Fu, S.; Zhang, N.; Fu, X.; Li, L. IFN-gamma-mediated inhibition of lung cancer correlates with PD-L1 expression and is regulated by PI3K-AKT signaling. Int. J. Cancer 2018, 143, 931-943. [CrossRef]

74. Lee, J.; Tam, H.; Adler, L.; Ilstad-Minnihan, A.; Macaubas, C.; Mellins, E.D. The MHC class II antigen presentation pathway in human monocytes differs by subset and is regulated by cytokines. PLOS ONE 2017, 12, e0183594. [CrossRef]

75. Singhal, S.; Stadanlick, J.; Annunziata, M.J.; Rao, A.S.; Bhojnagarwala, P.S.; O’Brien, S.; Moon, E.K.; Cantu, E.; Danet-Desnoyers, G.; Ra, H.J.; et al. Human tumor-associated monocytes/macrophages and their regulation of T cell responses in early-stage lung cancer. Sci. Transl. Med. 2019, 11. [CrossRef] 